\title{
How composition determines the properties of isodimorphic poly(butylene succinate-ran-butylene azelate) random biobased copolymers: from single to double crystalline random copolymers
}

\author{
Idoia Arandia ${ }^{1}$, Agurtzane Mugica ${ }^{1}$, Manuela Zubitur $^{2}$, Arantxa Arbe ${ }^{3}$, \\ Guoming Liu ${ }^{4}$, Dujin Wang ${ }^{4}$, Rosica Mincheva ${ }^{5}$, Philippe Dubois ${ }^{5}$, \\ Alejandro J. Müller ${ }^{1,6^{*}}$
}

${ }^{1}$ Institute for Polymer Materials (POLYMAT) and Polymer Science and Technology Department, Faculty of Chemistry, University of the Basque Country (UPV-EHU),

Paseo Manuel de Lardizabal 3, 20018 Donostia-San Sebastián, Spain

${ }^{2}$ Chemical and Environmental Engineering Department, Polytechnic School, University of the Basque Country (UPV/EHU), 2008 Donostia-San Sebastián, Spain

${ }^{3}$ Materials Physics Center (CSIC-UPV/EHU), Paseo Manuel de Lardizabal 5, 20018 Donostia-San Sebastián, Spain

${ }^{4}$ Beijing National Laboratory for Molecular Sciences, CAS Key Laboratory of Engineering Plastics, Institute of Chemistry, Chinese Academy of Sciences, Beijing, 100190, China

${ }^{5}$ Laboratory of Polymeric and Composite Materials, Center of Innovation and Research in Materials and Polymers (CIRMAP), University of Mons (UMONS), Place du Parc 20, 7000, Mons, Belgium

${ }^{6}$ IKERBASQUE, Basque Foundation for Science, Bilbao, Spain.

*Corresponding author 


\begin{abstract}
The structure, morphology and thermal properties of biobased and biodegradable poly(butylene succinate-ran-butylene azelate) random copolyesters with a wide composition range were studied. These PBS-ran-PBAz copolymers can crystallize in the entire composition range despite being random, displaying a eutectic point when their melting point is plotted as a function of composition. Wide Angle Xray Scattering (WAXS) studies confirmed isodimorphic behavior where PBS-rich copolymers crystallize with PBS type unit cells with some PBAz repeating units inclusions and vice versa for PBAz-rich copolymers. Away from eutectic compositions the copolymers exhibit only one crystalline phase (PBS-rich or PBAzrich crystalline phases) while at the eutectic point both phases can crystallize. The only double crystalline copolymer amongst those prepared had a composition close to the eutectic point of $45 \mathrm{~mol} \%$ PBS (and $55 \mathrm{~mol} \% \mathrm{PBAz}$ ). The crystallization of the two phases occurred in the same temperature range upon cooling from the melt at $10^{\circ} \mathrm{C} / \mathrm{min}$ in a DSC (i.e., coincident crystallization). Self-nucleation (SN) studies of the PBS-rich phase were performed. After SN, the separate crystallization of each phase was clearly observed during cooling from the self-nucleation temperature (i.e., PBS and PBAz-rich phases). Small Angle X-ray Scattering (SAXS) experiments were performed for the first time for this type of isodimorphic copolymers. The results show that the lamellar long period is a strong function of composition. While limited inclusions of PBAz units within the crystal lattice only cause a slight expansion of the PBS component unit cell, the increase of comonomer content produces an unexpected synergistic increase in long periods and lamellar thickness values.

In the case of the only double crystalline copolymer examined, the PBS-rich phase forms space filling spherulites (observed by Polarized Light Optical Microscopy, PLOM) at higher temperatures that template the superstructural morphology of the copolymer. These PBS-rich phase spherulites contain radial lamellar stacks whose long period was determined by SAXS. Upon further cooling, the PBAz-rich phase crystallizes in the intra-spherulitic amorphous regions with newly form lamellae that have their own distinct long period according to SAXS results. AFM observations of the PBS-rich crystalline lamellae confirmed the lamellar thickness and long spacings determined by SAXS. A schematic morphological model of the mixed spherulites produced by this double crystalline diblock copolymer is proposed based on the experimental evidences collected by SAXS, PLOM and AFM.
\end{abstract}

Keywords: biobased copolyesters, eutectic point, isodimorphism, double crystalline random copolymers, self-nucleation. 


\section{Introduction}

The protection of the environment has become a priority goal. Biodegradable polymers are materials with the required ecological characteristics to contribute to such a goal. ${ }^{1}$ Among these, the family of aliphatic polyesters is one of the most attractive because of their biodegradability and biocompatibility. They have attracted considerable attention and numerous research works have been published dealing with biodegradable aliphatic polyesters. ${ }^{2-4}$

Poly(butylene succinate) (PBS) is a promising biodegradable polyesters in view of its good mechanical properties that are comparable with low-density polyethylene and other polyolefins. ${ }^{5,6}$ However, PBS is characterized by high crystallinity, which causes a slow biodegradation rate. ${ }^{7}$ Thus, copolymerization has been used to limit its degree of crystallization and improve its physical properties to extend its application in the biodegradable polymer market. Therefore, the study of the crystallization behavior of PBS random copolymers is important in view of its strong correlation with biodegradation rates, mechanical properties and applications. ${ }^{8,9}$ The crystallization process of several random copolyesters, such as, poly(butylene succinate-ran-hexamethylene succinate), ${ }^{10}$ poly(butylene succinateran-adipate), ${ }^{11}$ poly(butylene succinate-ran-diethylene glycol succinate), ${ }^{12}$ poly(butylene succinate-ran-butylene fumarate), ${ }^{13}$ poly(butylene succinate-ranethylene succinate),${ }^{14}$ poly(butylene succinate-ran-propylene succinate $)^{15}$ and more recently, poly(butylene succinate-ran-butylene azelate ${ }^{16}$ has been studied.

Random copolymers constituted by two crystallizable units may show different crystallization behavior depending on their miscibility and ability to share crystal lattices. ${ }^{17}$ Comonomer units can be totally excluded and remain in the amorphous phase or cocrystallization may be observed if the comonomer units are 
similar in chemical structure, repeat-unit length, and/or crystal chain conformation. Two cases of cocrystallization behavior have been reported: isomorphism or isodimorphism. ${ }^{18,19}$

In the case of isomorphic copolymers, only one crystalline phase containing both comonomer units is observed and the crystal structure is the same in the entire composition range. On the other hand, for isodimorphic copolymers there are two crystal structures depending on composition. When the melting point is plotted as a function of composition a eutectic type of behaviour is commonly observed that corresponds to the composition at which a change in crystal structure occurs. In isodimorphic copolymers, at least one of the two crystalline phases incorporates part of the corresponding minor component in its crystalline lattice. Typically, the increase of minor comonomer concentration within each crystalline phase decreases the melting point and crystallinity of the copolymers. ${ }^{9}$

A recent addition to the biobased random co-polyesters family has been synthesized for the first time by Mincheva et al. ${ }^{20}$ They synthesized a wide range of poly(butylene succinate-ran-butylene azelate) copolymers (PBS-ran-PBAz) by a twostep polycondensation reaction. They demonstrated by NMR that the copolymers were ideally random and also that, in spite of being random, they were able to crystallize in the entire composition range. Very similar PBS-ran-PBAz random copolymers were synthesized by Díaz et al. ${ }^{16}$ with parallel results. They studied the structure of the copolymers by Wide Angle X-ray Scattering (WAXS) and performed non-isothermal and isothermal crystallization. ${ }^{16,21}$ In their work, there are results that indicate possible isodimorphic behavior, like a systematic variation of the crystalline unit cell density with copolymer composition and composition dependent changes of Lauritzen and Hoffman parameters for the overall isothermal crystallization. 
However, since the equilibrium melting points (obtained by Hoffman-Weeks extrapolations) were found to decrease according to the Baur exclusion model, ${ }^{22}$ they finally concluded that monomer exclusion was predominant during crystallization. Nevertheless, comonomer inclusion cannot be completely ruled out, especially under non-isothermal conditions. ${ }^{9}$ In fact, complete comonomer exclusion in truly random copolymers almost inevitably leads to the impossibility to crystallize for a range of intermediate copolymer compositions in non-iso(di)morphic copolymers.

In the present paper, we make use of the previously synthesized PBS-ranPBAz copolymers by Mincheva et al. $^{20}$ to study their structure, non-isothermal crystallization and morphology. We have performed Small Angle X-ray Scattering (SAXS), for the first time in this type of random copolymers, and have correlated the results with data obtained from WAXS, Polarized light Optical Microscopy (PLOM) and AFM. Our results indicate that at least some comonomer inclusion is present during non-isothermal crystallization and that the copolymers can be considered isodimorphic under such conditions. We show how composition determines the structure and morphology of these fascinating copolymers that can exhibit single or double crystalline behavior. We also propose a morphological model to describe the lamellar arrangement within the mixed spherulites formed by the double crystalline copolymer at a composition close to the eutectic point.

\section{Experimental}

\section{Materials}

The copolymers were synthesized and characterized, as recently reported by some of us (see Scheme 1). ${ }^{20}$ Succinic acid (SuA) and dimethyl azelate (DMAz) were copolymerized at $[\mathrm{COOH}]:\left[\mathrm{COOCH}_{3}\right]=1.0: 0,0.8: 0.2,0.6: 0.4,0.5: 0.5,0.4: 0.6$, 
0.2:0.8 and 0:1.0 molar ratios in the presence of 1,4-butane diol (BDO). The synthesis was performed by a two-stage melt polycondensation reaction: the first one, esterification at atmospheric pressure of SuA, DMAz, and BDO, and the second one, polycondensation at reduced pressure. Reactions were performed in a specially designed and adapted Inox ${ }^{\circledR}$ Autoclave reactor (Autoclave-France, France).

Samples are denoted in an abbreviated form, e.g., $\mathrm{BS}_{\mathrm{xx}} \mathrm{BAz}_{\mathrm{yy}}{ }^{\mathrm{zz}}$, indicating the molar ratio of each component as subscripts ( $\mathrm{xx}$ and $\mathrm{yy}$ ), and the molecular weight $\left(10^{3}, \mathrm{~g} / \mathrm{mol}\right)$ of the entire copolymer with superscripts $(\mathrm{zz})$.

(a)<smiles>CC(C)OCCCCOC(=O)CCC(C)(C)C</smiles>

(b)<smiles>CCOCCCCOC(=O)CCCCCCCCC(C)C</smiles><smiles>CC(C)=CCCCCCCC(=O)OCCCCOC(=O)CCC(=O)OCCCCC(C)(C)OC(C)(C)C</smiles>

Scheme 1. Chemical structures for the repeating units of: (a) poly(butylene succinate) (PBS), (b) poly(butylene azelate) (PBAz) and (c) PBSAz random copolymers.

\section{DSC Measurements}

The non-isothermal crystallization behavior of the polymer samples was determined by differential scanning calorimetry (DSC), using a Perkin-Elmer Pyris 1 calorimeter equipped with a refrigerated cooling system Intracooler $2 \mathrm{P}$, under nitrogen atmosphere flow and calibrated with indium. The samples were weighted and sealed in aluminum pan. Experiments were generally conducted in a temperature range between $-30^{\circ} \mathrm{C}$ and $145^{\circ} \mathrm{C}$ at a rate of $10^{\circ} \mathrm{C} / \mathrm{min}$ except where indicated in the text or for $T_{g}$ determinations (where a minimum temperature of $-100^{\circ} \mathrm{C}$ was used). 
Self-Nucleation (SN) Studies by DSC

Self-nucleation is a technique designed to enhance nucleation density. Crystal fragments or chain segments with residual crystal memory are the best nucleating source for any polymer. ${ }^{23-25}$ The SN procedure applied here consists of several steps: ${ }^{23-25}$

(a) Erasure of previous thermal history by heating the samples to $30{ }^{\circ} \mathrm{C}$ above their peak melting temperature for $3 \mathrm{~min}$. All thermally sensitive nuclei are destroyed in this step leaving only temperature-resistant heterogeneous nuclei.

(b) Creation of the initial "standard" semi-crystalline state by cooling the molten polymer at $10^{\circ} / \mathrm{min}$ down to $-30{ }^{\circ} \mathrm{C}$. The peak crystallization temperature is recorded during cooling and identified as the "standard" crystallization temperature (or standard $T_{c}$ ), since it is a function of the number density of thermally stable nuclei of the polymer sample.

(c) The sample is heated from $-30{ }^{\circ} \mathrm{C}$ up to a selected self-nucleation temperature (denoted $T_{s}$ ) at $10{ }^{\circ} \mathrm{C} / \mathrm{min}$, and then the sample is held at this $T_{s}$ temperature for 5 minutes. During this period of time at $T_{s}$, the sample could melt, self-nucleate or self-nucleate and anneal depending on the temperature value.

(d) Subsequent cooling at $10{ }^{\circ} \mathrm{C} / \mathrm{min}$ from $T_{s}$ down to $-30{ }^{\circ} \mathrm{C}$.

(e) Final melting. The sample is heated from $-30{ }^{\circ} \mathrm{C}$ to above its melting point at $10{ }^{\circ} \mathrm{C} / \mathrm{min}$ to record the full melting behavior.

The effects of the SN treatment can be assessed by examining the steps (d) and (e) above. Fillon et al. ${ }^{23}$ defined the so-called "Domains" of self-nucleation as:

Domain I (Complete Melting Domain). The polymer is in Domain I when complete melting occurs and the crystalline memory of the material is erased. 
Domain II (Exclusive Self-Nucleation Domain). When the $T_{s}$ temperature is able to self-nucleate the material without causing annealing, $T_{c}$ (the peak crystallization temperature) is shifted to higher temperatures while the subsequent melting does not show any signs of annealing. When the sample is within Domain II, an increase in nucleation density is obtained as indicated by the increase in $T_{c}$ values. The minimum $T_{s}$ temperature within Domain II is defined as the "Ideal SelfNucleation Temperature" $\left(T_{s, \text { ideal }}\right)$, since it is the temperature that causes maximum self-nucleation without annealing.

Domain III (Self-Nucleation and Annealing Domain). When $T_{s}$ is too low, partial melting is produced and the unmolten crystals anneal during the $5 \min$ at $T_{s}$.

\section{Polarized Light Optical Microscopy (PLOM)}

The spherulitic morphologies were observed by polarized light optical microscopy (PLOM) using a Leitz Aristomet polarized microscope equipped with polarizers and a sensitive red tint plate. A Mettler FP85Ht hot stage connected to a liquid nitrogen system was used to control the temperature. The samples were pressed on a glass slide and covered with a glass coverslip. They were heated to a temperature of $30^{\circ} \mathrm{C}$ above their DSC melting peak and they were kept at this temperature for 5 min to erase previous thermal history. Samples were then quickly cooled to the selected crystallization temperature. Micrographs were taken with a Leica DC420 digital camera.

Atomic Force Maicroscopy (AFM)

AFM measurements were performed using a Di_Veeco Multimode scanning probe microscope equipped with a Nanoscope IIIa controller. For AFM studies, the 
sample $\mathrm{BS}_{45} \mathrm{BAz}_{55}{ }^{38}$ (see Table 1) was spin-coated into a homogeneous thin film on a mica substrate from chloroform solution $(40 \mathrm{mg} / \mathrm{mL})$. The film was then melted to erase thermal history at $100^{\circ} \mathrm{C}$ for $5 \mathrm{~min}$. Then it was cooled at $10^{\circ} \mathrm{C} / \mathrm{min}$ until $35^{\circ} \mathrm{C}$. At this temperature, the sample was isothermally crystallized for $15.5 \mathrm{~h}$, and then cooled to room temperature. Height and phase images of spherulites were recorded in tapping mode using silicon TESP tips having a resonance frequency of approximately $320 \mathrm{kHz}$ and a cantilever spring constant about $42 \mathrm{~N} / \mathrm{m}$. The micrographs size was in a range of $1 \mu \mathrm{m}$ to $3 \mu \mathrm{m}$.

\section{$X$-ray Scattering}

Wide Angle X-Ray scattering measurements were performed on a Bruker D8 Advance diffractometer working in parallel beam geometry. By using a Göbel mirror, the originally divergent incident X-ray beam from a line focus X-ray tube $(\mathrm{Cu}$, operating at $40 \mathrm{kV}$ and $40 \mathrm{~mA}$ ) is transformed into an intense and parallel beam that is free of $\mathrm{K} \beta$ radiation. The parallel beam optics required in the secondary beam path is achieved by an equatorial axial Soller slit of $0.2^{\circ}$. The linear detector LYNXEYE used presents an active area of $14.4 \mathrm{~mm}$ x $16 \mathrm{~mm}$. Measurements were performed in reflection $\left(\theta-2 \theta\right.$ configuration) varying $2 \theta$ from 4 to $30^{\circ}$ with a step of $0.05^{\circ}$. The measuring time employed was 10 s/point. The films were placed in an Anton Paar TTK 450 Low-Temperature chamber under vacuum conditions allowing variations of the sample temperature between -193 and $450^{\circ} \mathrm{C}$ with $0.1^{\circ} \mathrm{C}$ resolution.

SAXS was used to probe the lamellar structure within the spherulites by determining their long periods. The experiments were conducted on a Rigaku 3pinhole PSAXS-L equipment operating at $45 \mathrm{kV}$ and $0.88 \mathrm{~mA}$. The MicroMax-002+ X-Ray Generator System is composed by a microfocus sealed tube source module and 
an integrated $\mathrm{X}$-Ray generator unit which produces $\mathrm{CuK} \alpha$ transition photons of wavelength $\lambda=1.54 \AA$. The flight path and the sample chamber in this equipment are under vacuum. The scattered X-Rays are detected on a two-dimensional multiwire XRay Detector (Gabriel design, 2D-200X). This gas-filled proportional type detector offers a $200 \mathrm{~mm}$ diameter active area with c.a. 200 micron resolution. The azimuthally averaged scattered intensities were obtained as a function of wave vector $\mathrm{q}, \mathrm{q}=4 \pi \lambda^{-1} \sin \theta$, where $\theta$ is half the scattering angle. Reciprocal space calibration was done using silver behenate as standard. Films were placed in a Linkam Scientific Instruments THMS 600 temperature controller (range: $-196^{\circ}$ to $600^{\circ} \mathrm{C}$, stability < $0.1^{\circ} \mathrm{C}$ ) in transmission geometry, with a sample to detector distance of $2 \mathrm{~m}$. Measuring times of 20 min were employed.

\section{Results and Discussion}

\section{Non-isothermal DSC measurements}

The standard non-isothermal behavior of neat PBS and PBAz homopolymers and PBS-ran-PBAz copolymers are presented in Figure 1. Table 1 lists all the relevant transition temperatures and enthalpies. The copolymers exhibited a single glass transition temperature $\left(T_{g}\right)$ (see Table 1) in between the $T_{g}$ values of the homopolymers, as expected for random copolymers that form a miscible amorphous phase. 
Table 1. Molar composition determined by ${ }^{1} \mathrm{H}$ NMR and thermal transitions determined by DSC (at $10^{\circ} \mathrm{C} / \mathrm{min}$ ) of the materials employed in this work. The melting enthalpies are normalized by composition in all cases. The crystallization enthalpies are also normalized by composition, except for the coincident crystallization case in sample $\mathrm{BS}_{45} \mathrm{BAz}_{55}{ }^{38}$

\begin{tabular}{|c|c|c|c|c|c|c|c|c|c|}
\hline \multirow[t]{2}{*}{ Code } & \multicolumn{2}{|c|}{$\begin{array}{c}\text { Composition } \\
\text { (PBS/PBAz), mol }\end{array}$} & \multicolumn{7}{|c|}{ DSC data } \\
\hline & Theoretical & $\begin{array}{c}\text { Exp. } \\
(\stackrel{1}{\mathrm{H}} \mathrm{NMR})\end{array}$ & $\begin{array}{c}T_{g} \\
\text { onset } \\
\left({ }^{\circ} \mathrm{C}\right)\end{array}$ & $\begin{array}{l}T_{m l} \\
\left({ }^{\circ} \mathrm{C}\right)\end{array}$ & $\begin{array}{l}T_{m 2} \\
\left({ }^{\circ} \mathrm{C}\right)\end{array}$ & $\begin{array}{c}\Delta H_{m 1} \\
(\mathrm{~J} / \mathrm{g})\end{array}$ & $\begin{array}{c}\Delta H_{m 2} \\
(\mathrm{~J} / \mathrm{g})\end{array}$ & $\begin{array}{c}T_{c} \\
\left({ }^{\circ} \mathrm{C}\right)\end{array}$ & $\begin{array}{l}\Delta H_{c} \\
(\mathrm{~J} / \mathrm{g})\end{array}$ \\
\hline $\mathrm{BS}^{25}$ & $1 / 0$ & $1 / 0$ & -36 & 114.7 & -- & 66 & & 75.0 & 69 \\
\hline $2 \mathrm{BS}_{82} \mathrm{BAz}_{18}^{22}$ & $0.8 / 0.2$ & $0.82 / 0.18$ & -50 & 98.0 & -- & 70 & -- & 58.7 & 72 \\
\hline $3 \mathrm{BS}_{61} \mathrm{BAz}_{39}{ }^{31}$ & $0.6 / 0.4$ & $0.61 / 0.39$ & -56 & 72.3 & -- & 70 & -- & 12.4 & 79 \\
\hline $4 \mathrm{BS}_{58} \mathrm{BAz}_{42}{ }^{37}$ & $0.5 / 0.5$ & $0.58 / 0.42$ & -57 & 60.3 & -- & 74 & & 3.2 & 77 \\
\hline $5 \mathrm{BS}_{45} \mathrm{BAz}_{55}^{38}$ & $0.4 / 0.6$ & $0.45 / 0.55$ & -61 & 46.3 & 26.4 & 72 & 57 & 9.4 & 57 \\
\hline $6 \mathrm{BS}_{25} \mathrm{BAz}_{75}{ }^{40}$ & $0.2 / 0.8$ & $0.25 / 0.75$ & -62 & -- & 34.4 & -- & 80 & 16.2 & 67 \\
\hline $7 \quad \mathrm{BAz}^{43}$ & $0 / 1$ & $0 / 1$ & -63 & -- & 41.2 & -- & 65 & 21.6 & 58 \\
\hline
\end{tabular}




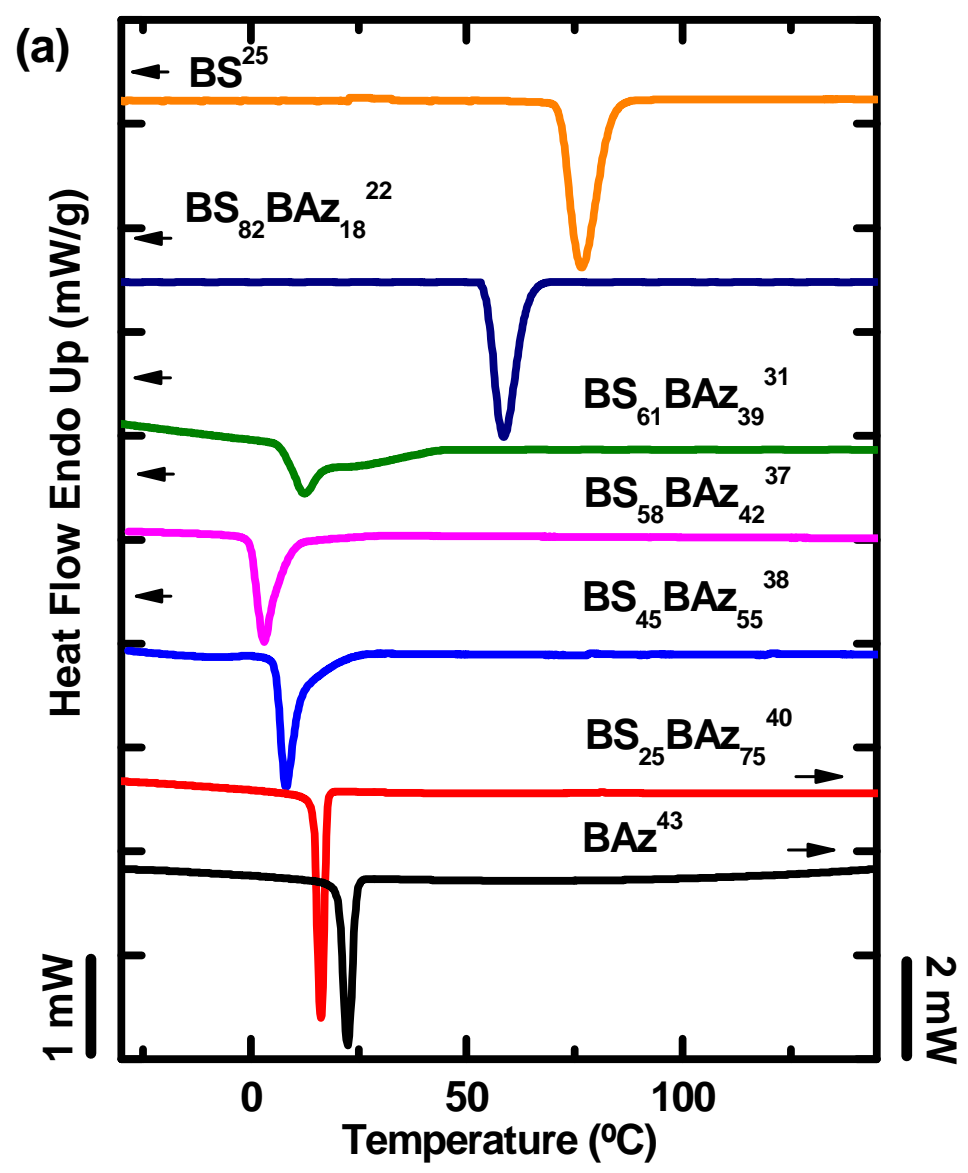




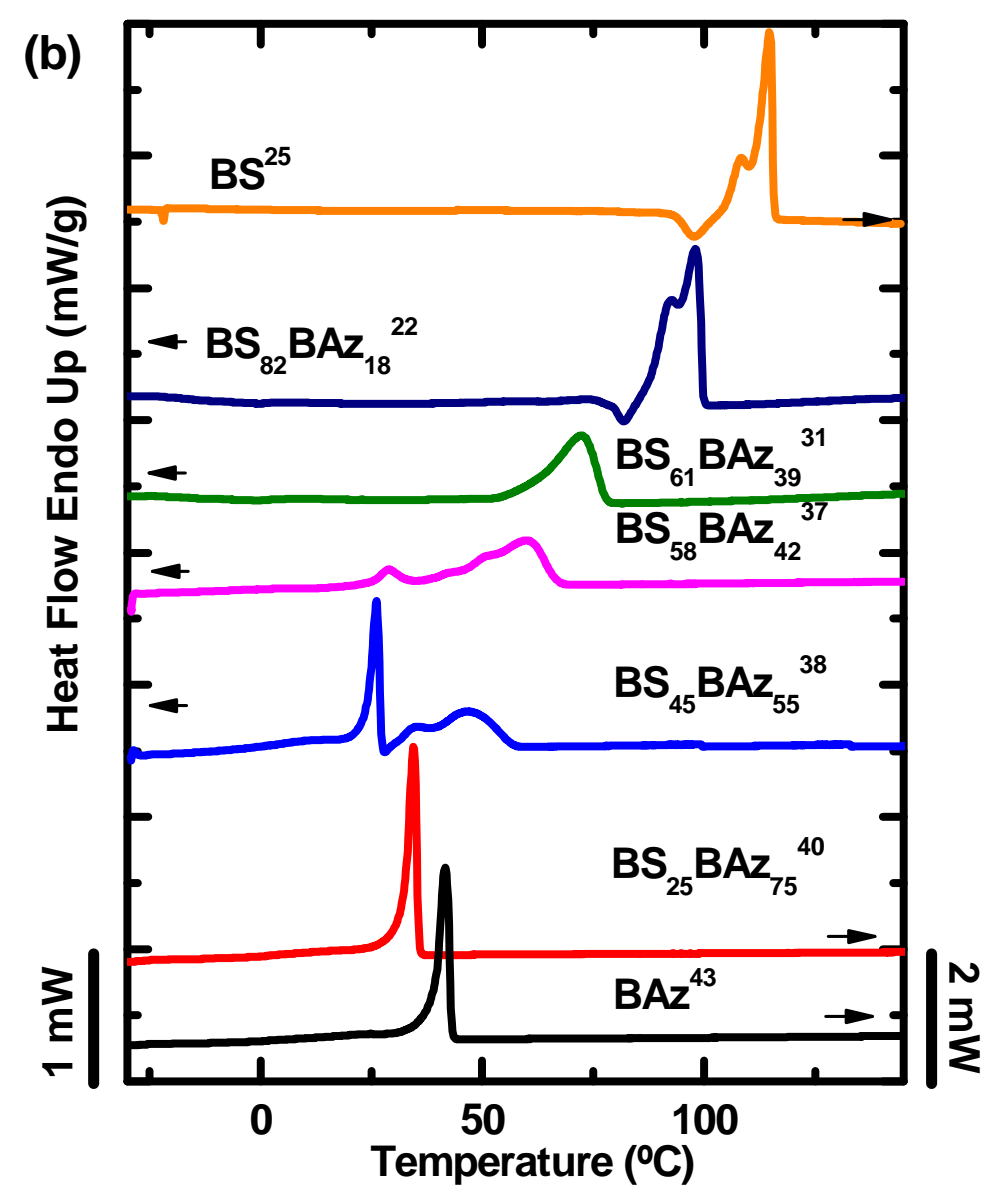

Figure 1. (a) Cooling DSC scans from the melt and (b) subsequent heating scans for the indicated homopolymers and random copolymer samples. Scanning rates: $10^{\circ} \mathrm{C} / \mathrm{min}$.

Even though the prepared copolymers are random, as demonstrated previously by ${ }^{13} \mathrm{C} \mathrm{NMR},{ }^{20}$ all samples were able to crystallize, and their crystallization and melting temperatures were found to be a strong function of composition. The results are consistent with previous works. ${ }^{16,20,21}$

One way to explain why the copolymers can crystallize in the entire composition range is to consider that the PBS-ran-PBAz copolymers are isodimorphic and therefore can crystallize in crystalline unit cells that resemble those of the homopolymers, but with inclusions of the second component repeating units. 
Figure 1a shows that all materials exhibit a main sharp crystallization peak during cooling from the melt that in some cases contains a high temperature shoulder or tail, like in $\mathrm{BS}_{61} \mathrm{BAz}_{39}{ }^{31}$ and $\mathrm{BS}_{45} \mathrm{BAz}_{55}{ }^{38}$.

The subsequent heating scans, after cooling from the melt (Figure 1a), are presented in Figure 1b. PBS exhibits cold crystallization during the scan followed by a double melting peak. The presence of two melting peaks could be due to a partial melting and recrystallization process during the heating scan or to the melting of two populations with different mean lamellar thickness (one lamellar population formed during the cooling scan in Figure 1a and the second during the cold crystallization process in Figure 1b). Neat PBAz displays a single sharp melting endotherm that is consistent with its previous comparably sharp crystallization exotherm (Figure 1a).

When $\mathrm{BAz}$ is incorporated in the copolymer, the melting of the crystalline PBS phase is depressed to lower temperatures because PBS linear sequences are frequently interrupted by PBAz repeating units. However, since at high PBAz incorporation (for copolymers where PBAz content is between 39 to 55\%), the PBS phase is still undergoing crystallization, it is possible that PBS crystals incorporate some randomly distributed repeating units of BAz. In fact, WAXS results to be presented below confirm the inclusion of PBAz into PBS-rich crystalline phase (see below). We will refer to those copolymeric PBS crystals (that contain PBAz moieties in their unit cells) as PBS-rich crystalline phase.

WAXS results (to be presented below) indicate that only PBS-rich crystals are formed in the samples with $58 \%$ or more PBS content. On the other hand, both WAXS and DSC show that $\mathrm{BS}_{45} \mathrm{BAz}_{55}{ }^{38}$ is the only copolymer that is able to form both PBS-rich and PBAz-rich phase crystals. Finally, the copolymer with 75\% PBAz contains only PBAz-rich crystals. 


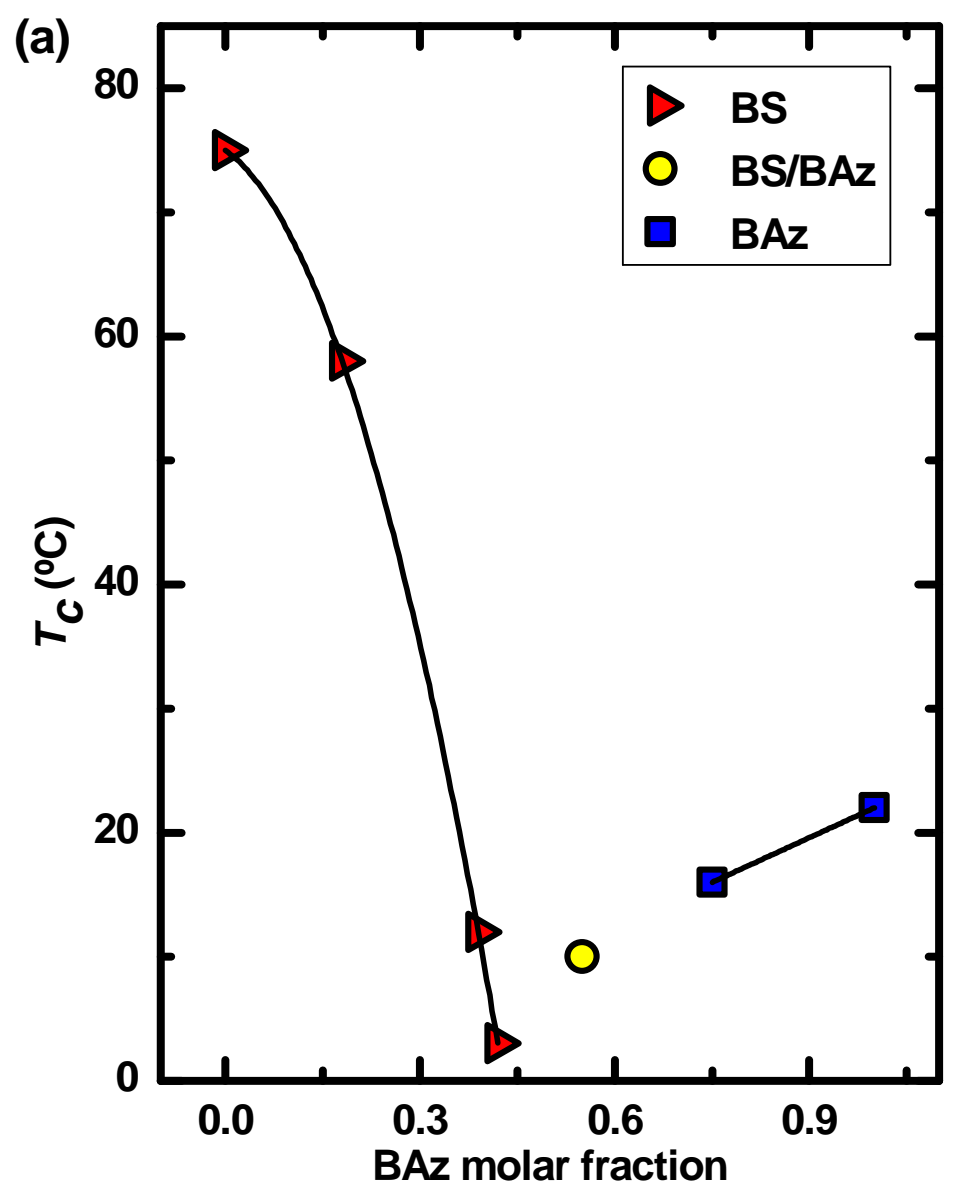




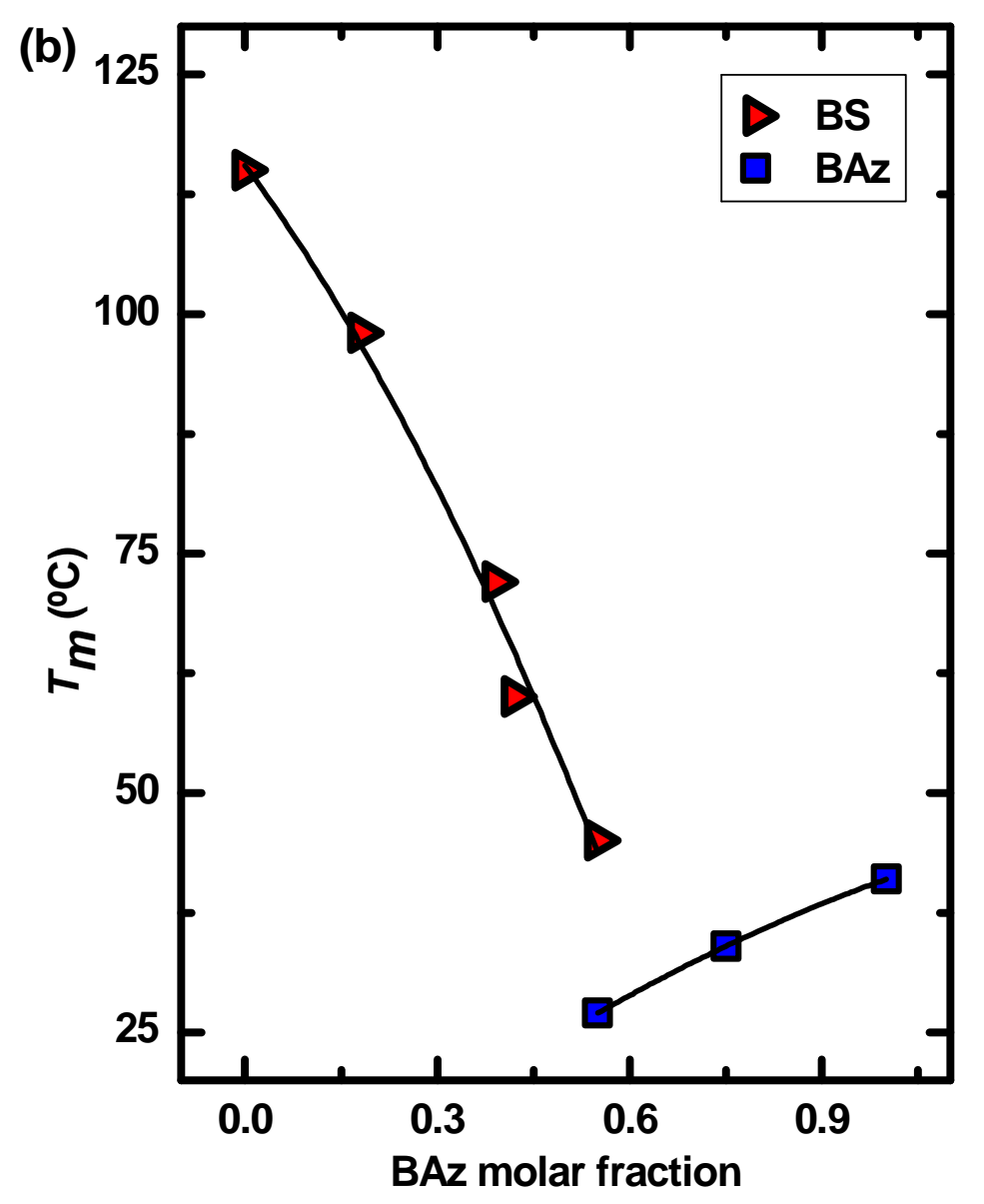

Figure 2. Peak crystallization (a) and melting (b) temperatures as a function of copolymer composition.

Figure 2 shows plots of crystallization (Figure 2a) and melting (Figure 2b) temperatures as a function of composition, with legends identifying the crystalline phases in accordance with parallel WAXS experiments (presented below). The presence of a eutectic point is readily apparent and has been reported for several isodimorphic copolyesters. $^{9}$

Figure 2 illustrates the tremendous potential of the thermal properties of isodimorphic copolymers. By a careful choice of composition, the melting point and 
therefore the applications of these biobased copolymers can be tailored from room temperature to $100^{\circ} \mathrm{C}$.

According to the thermal behavior presented in Figure 2, the eutectic point should be very close to $55 \% \mathrm{BAz}$ content. For copolymers where the random copolymer chains contain a majority of BS repeating units (i.e., whose composition is lower or equal to $42 \% \mathrm{BAz}$ ), PBS dominates the copolymer structural behavior. In these cases, the crystals with a large amount of BS repeating units (and a small amount of BAz "impurities" within their unit cells) will be thermodynamically favored and in fact, only PBS type crystals are formed according to WAXS (see below). On the other hand, for compositions with more than $55 \% \mathrm{BAz}$, only PBAz like crystals can form. For compositions near the eutectic point both crystalline phases can be produced in double crystalline random copolymers.

For the $\mathrm{BS}_{45} \mathrm{BAz}_{55}{ }^{38}$ copolymer, whose composition is near the eutectic point, coincident crystallization of both phases occurs. This means that the crystallization exotherms of the PBS and the PBAz-rich phase overlap (see Figure 1a) and as a result a single point is plotted in Figure 2a, since only one crystallization peak is observed (even though the exotherm is broad and asymmetric). During the heating scan (Figure 1b) fully separate melting of PBAz and PBS-rich crystalline phases is clearly seen and two melting points were plotted in Figure $2 b$ at the corresponding composition for $55 \%$ BAz. This is the only copolymer that is able to develop a double crystalline structure because it is close to the eutectic point where both phases have similar chances for crystallization. It would be highly unlikely that a random copolymer with an almost symmetric composition exhibits the crystallization of its two components without isodimorphic behavior (i.e., some comonomer inclusion must be present in both phases as confirmed by WAXS below). 
A closer look at the coincident crystallization of both phases within $\mathrm{BS}_{45} \mathrm{BAz}_{55}{ }^{38}$ is presented in Figure 3. Figure 3a shows cooling scans from the melt at $10^{\circ} \mathrm{C} / \mathrm{min}$ that are stopped at specific temperatures followed by immediate reheat scans (also at $10^{\circ} \mathrm{C} / \mathrm{min}$ ) to record the melting behavior, see Figure $3 \mathrm{~b}$.

When $\mathrm{BS}_{45} \mathrm{BAz}_{55}{ }^{38}$ is cooled down to $-30^{\circ} \mathrm{C}$, both phases crystallize until saturation (at $10^{\circ} \mathrm{C} / \mathrm{min}$ ). The cooling DSC scan in Figure $3 \mathrm{a}$ shows a wide crystallization exotherm with a high temperature shoulder (between 25 and $12.5^{\circ} \mathrm{C}$ ), a sharp peak at approximately $9^{\circ} \mathrm{C}$, and a broad weak crystallization exotherm between 0 and $-25^{\circ} \mathrm{C}$ (seen only in a close-up indicated with an arrow). The subsequent heating scan shown in Figure $3 b$ clearly demonstrates the melting of both PBAz-rich crystalline phase (in a broad bimodal melting range, with a low intensity first peak between -10 and $27^{\circ} \mathrm{C}$, hence a close-up is provided, and a sharp second peak at $26^{\circ} \mathrm{C}$ aprox.) and PBS-rich crystalline phase (with a broad bimodal melting peak between 27 and $\left.56^{\circ} \mathrm{C}\right)$. 


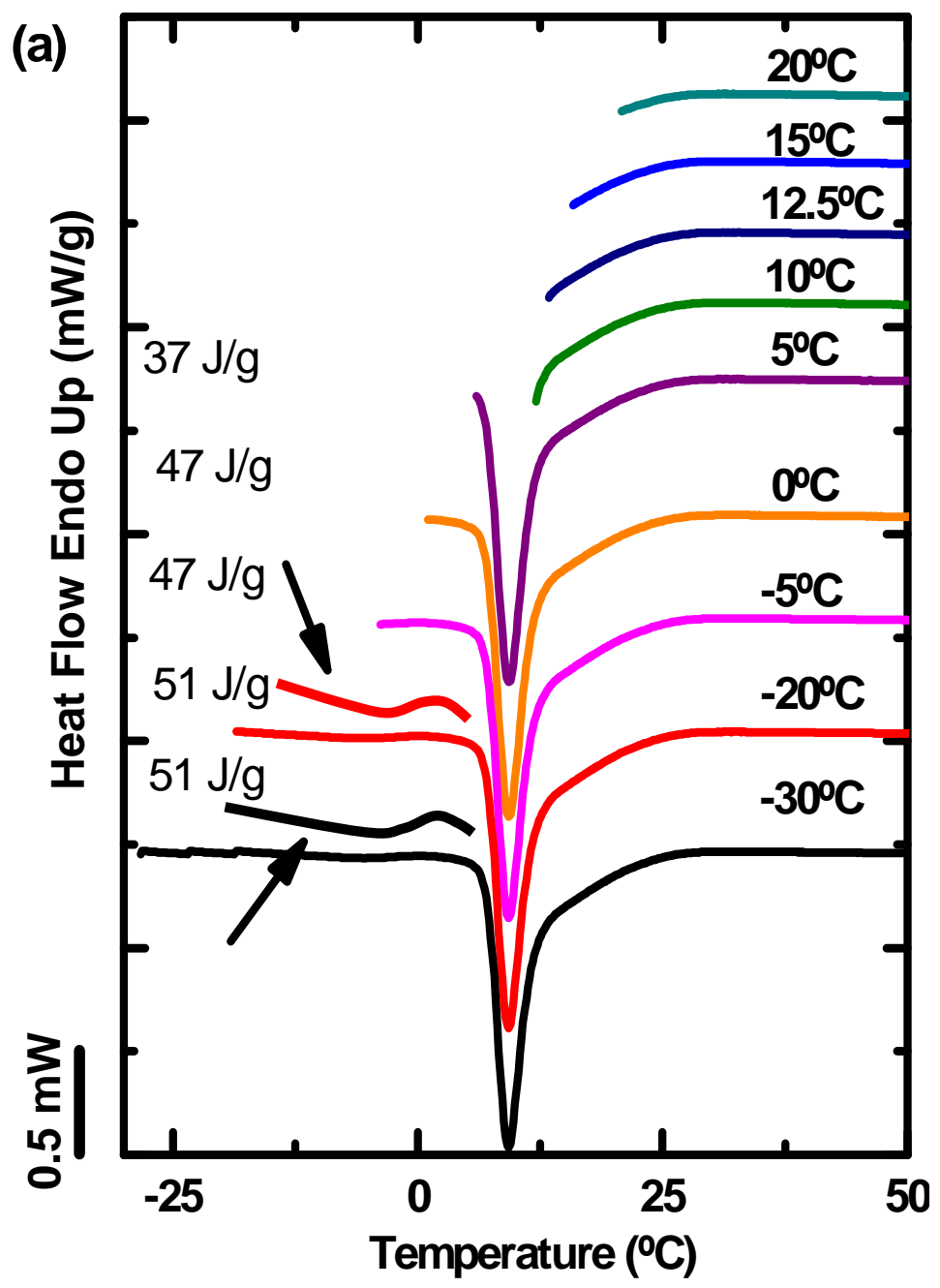




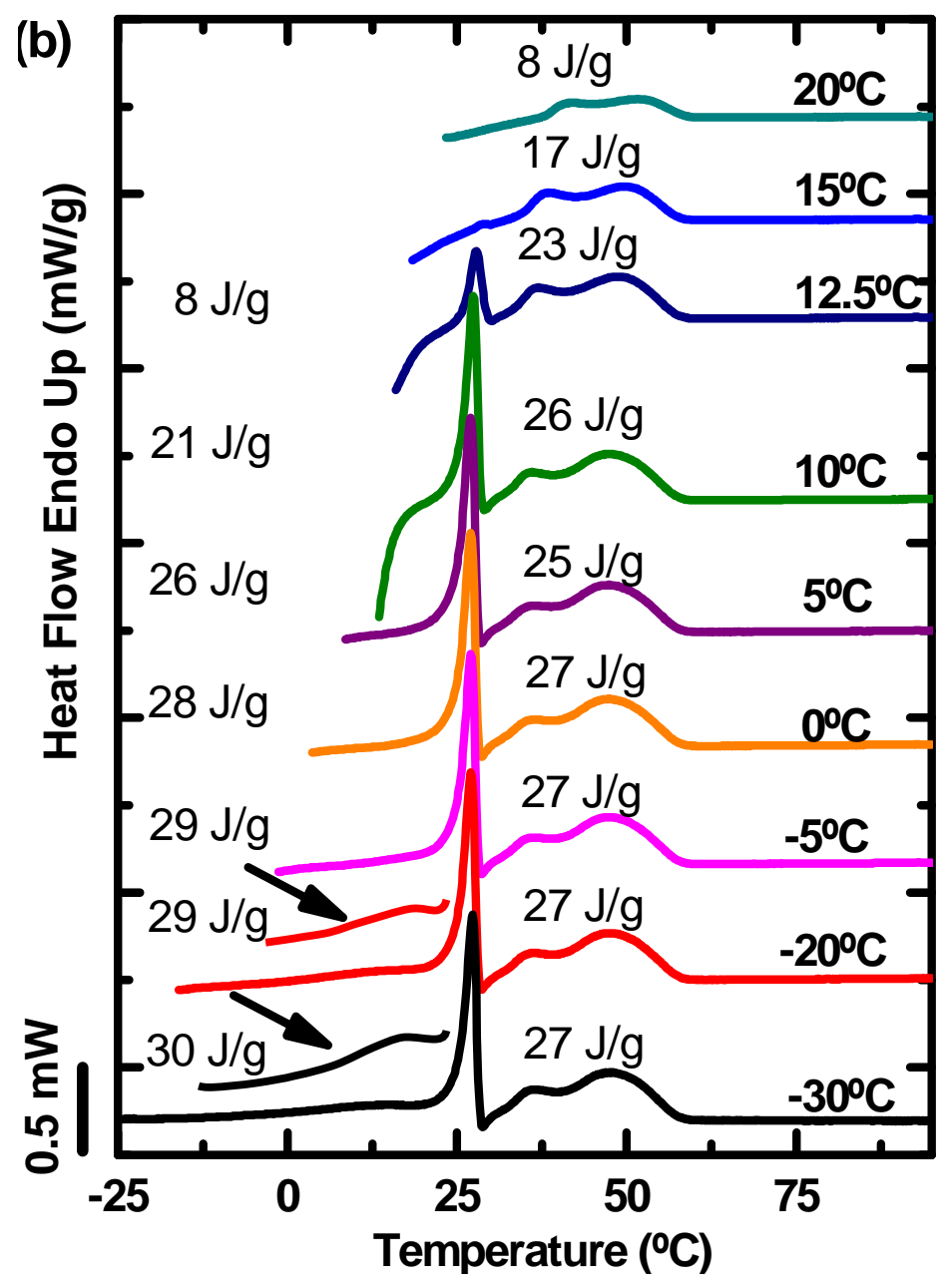

Figure 3. (a) DSC cooling scans for the double crystalline $\mathrm{BS}_{45} \mathrm{BAz}{ }_{55}{ }^{38}$ that exhibits coincident crystallization. The legend contains the total crystallization enthalpy (left hand side) and the final temperature of the scan (right hand side). (b) Subsequent DSC heating scans. The legend contains the melting enthalpy of the PBAz-rich phase (low temperature melting peak at approx. $26^{\circ} \mathrm{C}$ ) and the PBS-rich phase (bimodal melting peak in the range $29-60^{\circ} \mathrm{C}$ ) without normalizing by composition. The legend also includes (right hand side) the starting temperature for the scan. Scanning rate: $10^{\circ} \mathrm{C} / \mathrm{min}$.

The complex thermal behavior of $\mathrm{BS}_{45} \mathrm{BAz}_{55}{ }^{38}$ can be understood by comparing Figure $3 \mathrm{a}$ and Figure $3 \mathrm{~b}$ :

(a) Upon cooling from the melt, only PBS-rich phase crystallizes as long as the sample is cooled down to $20^{\circ} \mathrm{C}$ (see data for cooling and subsequent heating scans from the melt down to 20 and $15^{\circ} \mathrm{C}$, the first two traces at the top of Figures $3 \mathrm{a}$ and $3 \mathrm{~b}$ 
and their corresponding enthalpy values). Notice the total absence of a melting peak for the PBAz-rich phase for the top DSC trace corresponding to $20^{\circ} \mathrm{C}$ in Figure $3 \mathrm{~b}$. In the case of $15^{\circ} \mathrm{C}$, a very small melting peak corresponding to the PBAz-rich phase crystals fusion was detected.

(b) The PBAz-rich phase can only start its crystallization from the melt when cooled down to temperatures of at least $15^{\circ} \mathrm{C}$ (see above) and below, in a coincident fashion with the PBS-rich phase (see the corresponding DSC traces labeled with $15^{\circ} \mathrm{C}$ and $12.5^{\circ} \mathrm{C}$ in Figure $3 \mathrm{a}$ ). Upon subsequent heating from $12.5^{\circ} \mathrm{C}$, note the small but clear melting peak at approximately $26^{\circ} \mathrm{C}$ that corresponds to the PBAz-rich crystals fusion in Figure $3 b$.

(c) The PBS-rich phase achieves its maximum degree of crystallinity when cooled down to $10^{\circ} \mathrm{C}$ according to Figure $3 \mathrm{~b}$. The enthalpy values reported in Figure $3 b$ for the melting of the PBS-rich phase increase as the sample is cooled to progressively lower temperatures and then become constant within the error of the measurements at temperatures of $10^{\circ} \mathrm{C}$ or below $(25-27 \mathrm{~J} / \mathrm{g})$.

(d) The PBAz-rich phase keeps crystallizing all the way down to $-30^{\circ} \mathrm{C}$, although most of the crystallization had already occurred at $0^{\circ} \mathrm{C}$.

(e) The main crystallization peak at $9^{\circ} \mathrm{C}$ in Figure 3 a occurs in a temperature range where both phases crystallize simultaneously or coincidentally.

Coincident crystallization processes have also been found in double crystalline diblock copolymers that are either miscible in the melt or in the weak segregation regime. ${ }^{26-29}$ Following these previous works, we decided to employ the self-nucleation technique $e^{23,24}$ to try to separate the individual crystallization process for each phase. 


\section{Self-nucleation Behavior of PBS and Double Crystalline $\mathrm{BS}_{45} B A z_{55}^{38}$}

To illustrate the self-nucleation process with a simple case, we first applied this technique (as described in the experimental part) to neat PBS.

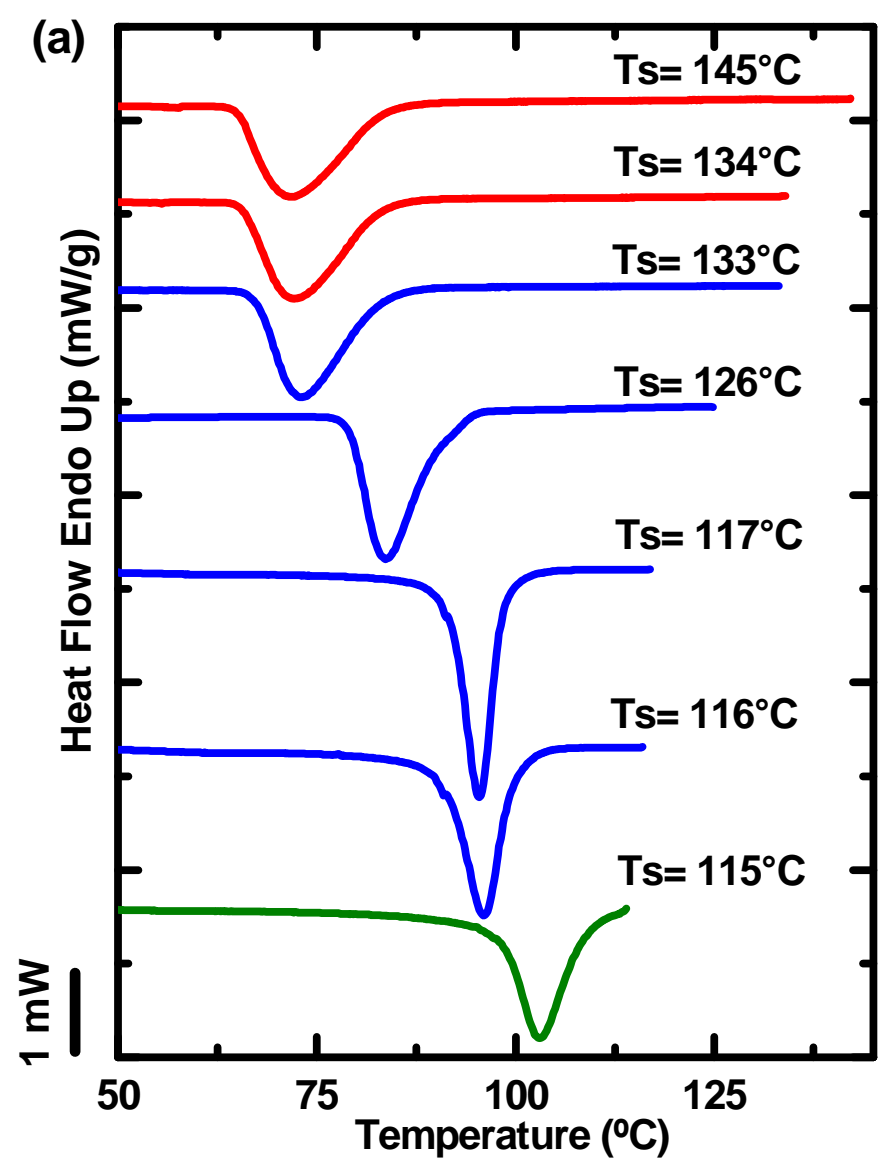




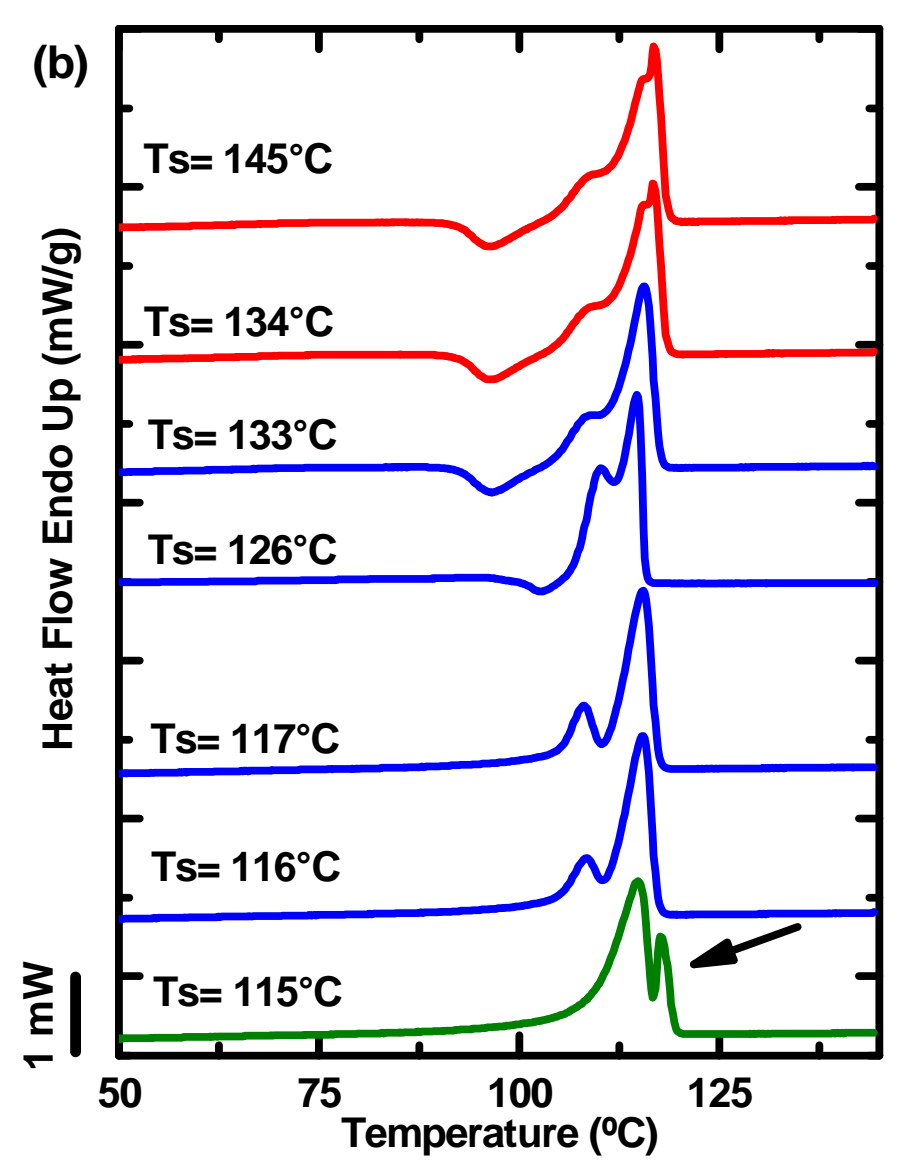

Figure 4. Self-nucleation of PBS homopolymer: (a) DSC cooling scans from the indicated self-nucleation $\left(T_{s}\right)$ temperatures and (b) subsequent heating scans at $10^{\circ} \mathrm{C} / \mathrm{min}$.

Figure 4a shows cooling scans from selected $T_{s}$ temperatures. At temperatures of $134^{\circ} \mathrm{C}$ and above, crystalline memory is completely erased and only high temperature resistant heterogeneities capable of nucleating the polymer during cooling remain. As a consequence, the peak crystallization temperature is constant in Figure $4 \mathrm{a}$ for these $T_{s}$ temperatures and the melting traces are invariant upon subsequent heating, as seen in Figure 4b. The described behavior occurs for $T_{s}$ values equal or larger than $134^{\circ} \mathrm{C}$, when the sample is within the complete melting domain (Domain I). 
When $T_{s}$ temperatures lower than $134^{\circ} \mathrm{C}$ (but higher than or equal to $116^{\circ} \mathrm{C}$ ) are employed, PBS experiences only self-nucleation, and its crystallization temperature increases (Figure 4a). The corresponding maximum peak melting point in Figure $4 \mathrm{~b}$ does not show signs of annealing. Therefore, the sample falls under the exclusive self-nucleation domain (Domain II). For higher $T_{s}$ values within Domain II, like $133^{\circ} \mathrm{C}$, the melting process of the sample upon subsequent heating (after the cooling from $T_{s}$ shown in Figure 4a) does not change significantly, since cold crystallization is still observed in Figure $4 \mathrm{~b}$. However, at further decrease in $T_{s}$ values within Domain II, cold crystallization disappears from the heating DSC trace and the double melting process is more pronounced (see for example the DSC traces corresponding to $\mathrm{Ts}=117$ or $116^{\circ} \mathrm{C}$ in Figure $4 \mathrm{~b}$ ). This is a consequence of an increase in the crystallization enthalpy produced during cooling from these lower $T_{s}$ values as a result of the self-nucleation effect (compare the crystallization exotherms in Figure 4a for the samples cooled from $T_{s}$ values $133^{\circ} \mathrm{C}$ and $117^{\circ} \mathrm{C}$ for example).

Finally when the $T_{s}$ temperature is lower or equal to $115^{\circ} \mathrm{C}$, partial melting occurs and the unmelted crystals experience annealing during the 5 min holding time at $T_{s}$, the sample is then in the self-nucleating and annealing domain (Domain III). This is easily distinguished by the appearance of a high temperature additional melting peak, signaled with an arrow in Figure $4 \mathrm{~b}$. 


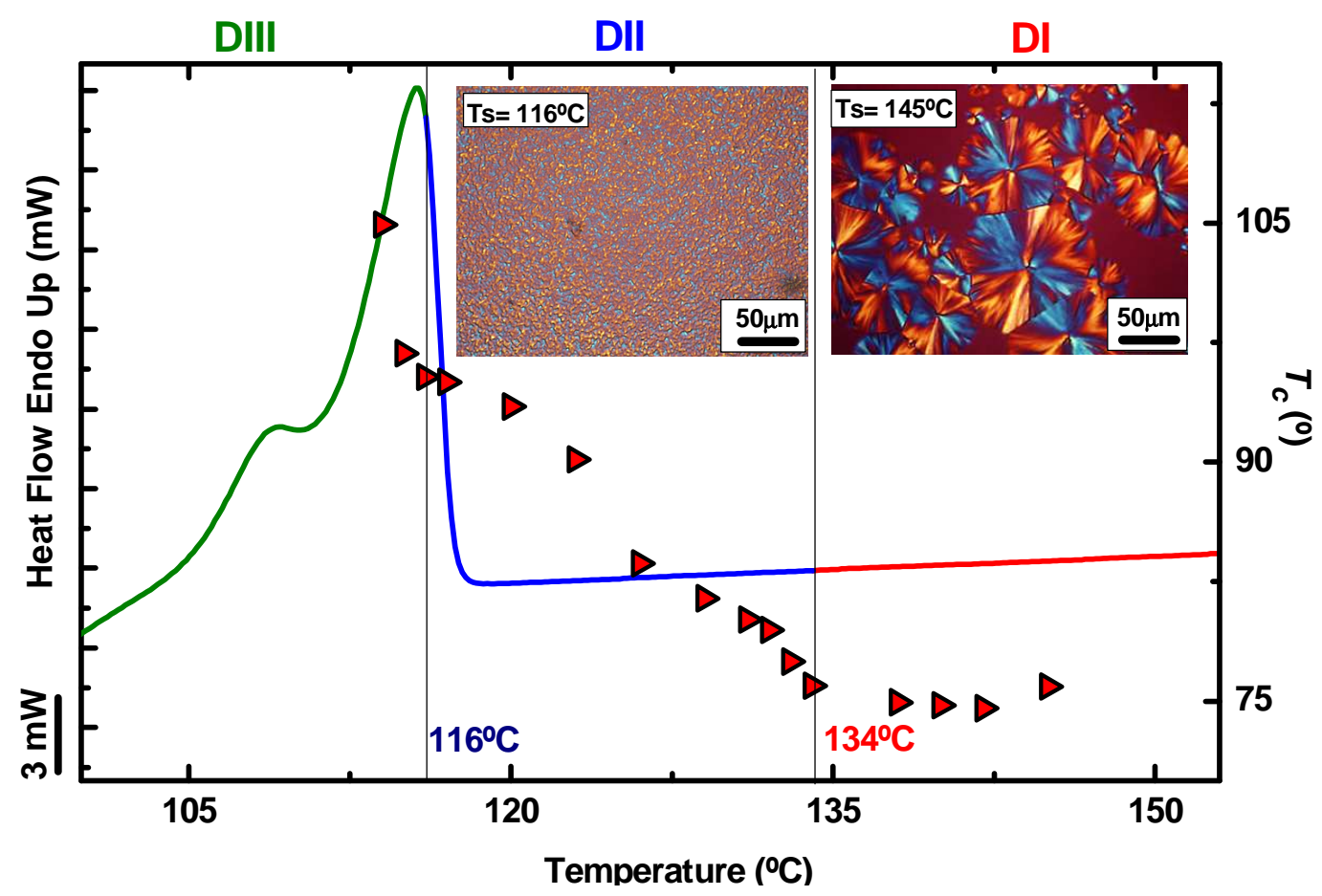

Figure 5. Representation of the self-nucleation domains for PBS homopolymer on top of the standard DSC melting trace. Insets include PLOM micrographs taken during cooling from $T_{s}=145^{\circ} \mathrm{C}$ (Domain $I$ ) and $T_{s}=116^{\circ} \mathrm{C}$ (Domain II). The data points represent peak crystallization temperatures (plotted on the right hand side $\mathrm{y}$ axis) as a function of $T_{s}$ values (plotted on the $\mathrm{x}$ axis).

Figure 5 illustrates the changes in peak crystallization temperatures as a function of $T_{s}$ values (see right hand side y axis for $T_{c}$ values and $\mathrm{x}$ axis for $T_{s}$ values). Crossing from Domain I to Domain II causes a large increase in $T_{c}$ that is proportional to the exponential increase in nucleation density that occurs during selfnucleation. ${ }^{23,24}$ When the sample enters Domain III, $T_{c}$ values increase further while the unmelted crystal population is annealed.

Figure 5 also shows the standard DSC melting trace of the PBS homopolymer employed in this work where the different self-nucleation domains have been indicated by color codes (red for Domain I, blue for Domain II and green for Domain III, the same color codes are employed in Figure 4) while the domain transitions are 
marked by vertical lines. It is remarkable how Domain II extends to temperatures well above the end of PBS melting. The self-nuclei in the temperature region between 120 and $133^{\circ} \mathrm{C}$ cannot be crystalline in nature and must be produced by residual chain segmental orientation in the melt as a result of a crystalline memory phenomenon. ${ }^{25}$

Two representative polarized light optical microscopy (PLOM) micrographs are inserted in Figure 5 to illustrate the enhancement in nucleation density. The micrographs were taken during cooling from $145^{\circ} \mathrm{C}$ (Domain I) or from $116^{\circ} \mathrm{C}$ (Domain II) at the same cooling rate of $10^{\circ} \mathrm{C} / \mathrm{min}$. The superstructural aggregates are clear negative spherulites partially or totally impinged with one another in Domain II. The much higher number of spherulites in the self-nucleated sample is readily seen, as the number of spherulites is proportional to the number of active nuclei (i.e., each spherulite is nucleated by one active heterogeneous nuclei). The $T_{s}$ value of $116^{\circ} \mathrm{C}$ is the lowest $T_{s}$ value within Domain II or the ideal self-nucleation temperature, i.e., the $T_{s}$ temperature that causes maximum self-nucleation without annealing. Therefore, it is not surprising that very small spherulites were produced upon cooling after selfnucleation at $116^{\circ} \mathrm{C}$.

Similar self-nucleation experiments were performed to the PBS-rich phase of the $\mathrm{BS}_{45} \mathrm{BAz}_{55}{ }^{38}$ copolymer and are presented in Figure 6 with similar color codes as those employed to indicate the self-nucleation domains in Figures 4 and 5. 

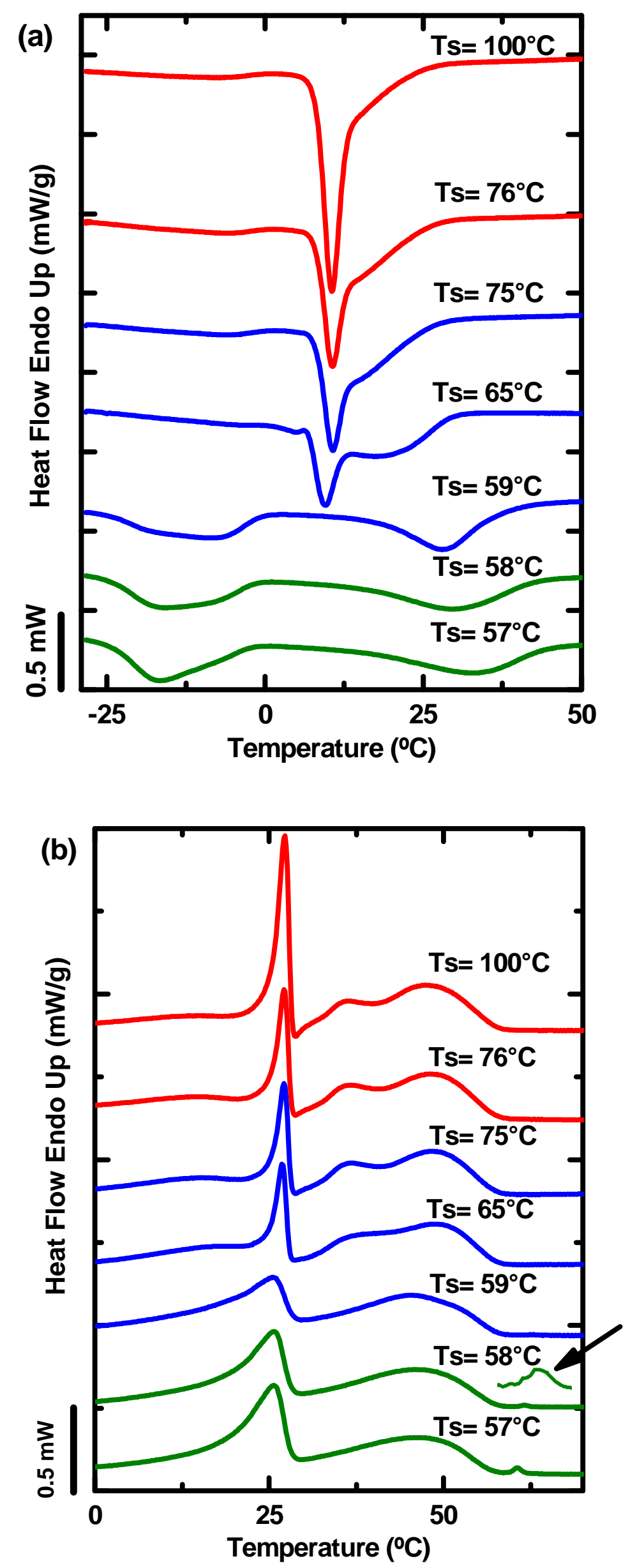
Figure 6. Self-nucleation of the PBS-rich crystalline phase within $\mathrm{BS}_{45} \mathrm{BAz}_{55}{ }^{38}$ : (a) DSC cooling scans from the indicated self-nucleation $\left(T_{s}\right)$ temperatures and $(\mathrm{b})$ subsequent heating scans at $10^{\circ} \mathrm{C} / \mathrm{min}$.

Figure 6a shows that when the PBS-rich phase is self-nucleated, within Domain II, its peak crystallization temperature (originally at approximately $9^{\circ} \mathrm{C}$ ) increases as $T_{s}$ decreases. A large part of the main exotherm shifts due to selfnucleation to higher $T_{c}$ temperatures (at $T_{s}=59^{\circ} \mathrm{C}$, the peak crystallization temperature of the PBS-rich phase is above $25^{\circ} \mathrm{C}$ ). At the same time a low temperature crystallization exotherm develops at temperatures below $0^{\circ} \mathrm{C}$ that corresponds to the crystallization of the PBAz-rich phase. Upon comparing in Figure 6a the DSC cooling curves from $T_{s}=100^{\circ} \mathrm{C}$ (Domain I) and $T_{s}=59^{\circ} \mathrm{C}$ (Domain II), it is clear that selfnucleation has helped achieved the separate crystallization of each phase. However, the PBS-rich phase that after self-nucleation crystallizes at much higher temperatures does not nucleate the PBAz-rich phase, as it could have been anticipated. On the contrary, the self-nucleated PBS-rich phase anti-nucleates the PBAz-rich phase, as will be also evidenced below in Figures 7.

Figure $6 \mathrm{~b}$ shows the subsequent DSC heating scans, after the cooling runs performed in Figure 6a. The self-nucleation process produces, besides a separate crystallization, a broadening of the PBAz-rich phase melting (i.e., the melting process occurring between 0 and $27^{\circ} \mathrm{C}$ ) when $T_{s}$ temperatures are in the lower range of Domain II (at $\left.59^{\circ} \mathrm{C}\right)$.

The self-nucleation domains of the PBS-rich phase within $\mathrm{BS}_{45} \mathrm{BAz}_{55}{ }^{38}$ are schematically shown by vertical lines on top of the DSC standard heating scan of the material presented in Figure 7a. The crystallization peak temperatures corresponding to the self-nucleation of the material are also presented in Figure 7a. In Domain I 
coincident crystallization occurs and only one $T_{c}$ value is plotted in Figure $7 \mathrm{a}$. When the material is self-nucleated, an interesting behavior is observed. As the PBS-rich phase is self-nucleated, its $T_{c}$ value is greatly increased as $T_{s}$ decreases as expected. However, the peak crystallization temperature of the PBAz-rich phase is seen to dramatically decrease as $T_{s}$ decreases, an evidence of anti-nucleation.

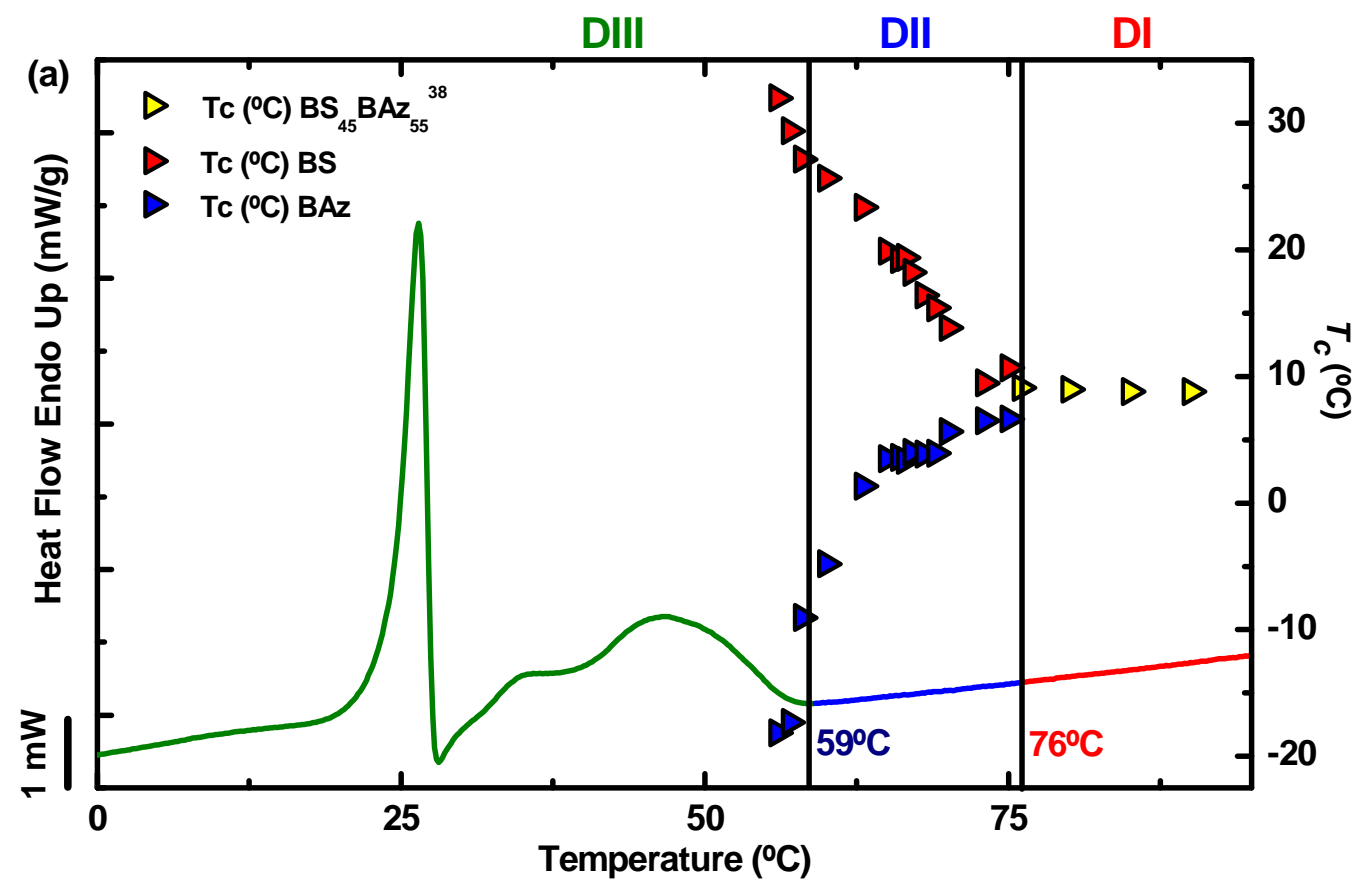




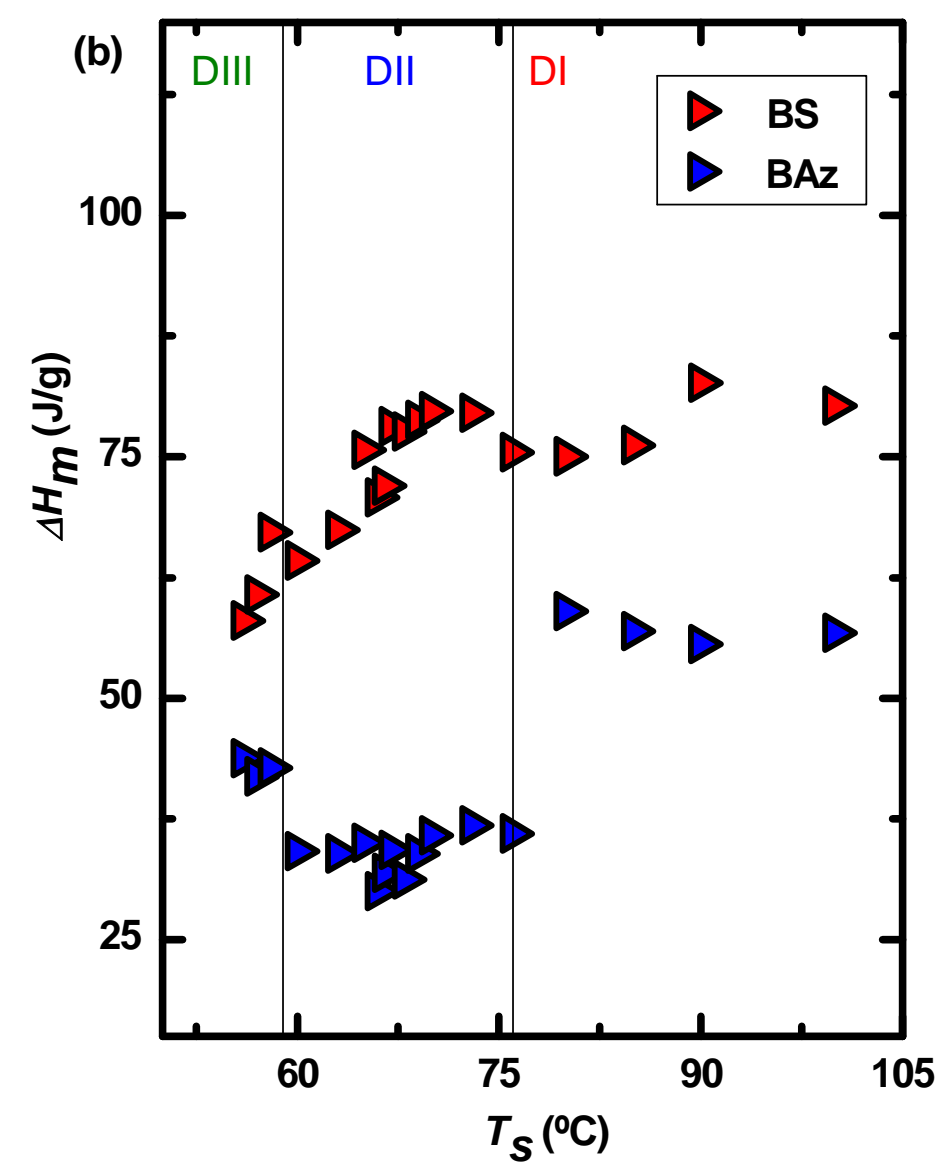

Figure 7. (a) Representation of the self-nucleation domains for the PBS-rich crystalline phase within $\mathrm{BS}_{45} \mathrm{BAz}_{55}{ }^{38}$ on top of a standard DSC melting trace for the copolymer. The data points represent peak crystallization temperatures for the indicated phases (plotted on the right hand side y axis) as a function of $T_{s}$ values (plotted on the $\mathrm{x}$ axis). (b) Melting enthalpies (normalized by composition) obtained during the subsequent heating scans after self-nucleation plotted as a function of selfnucleation temperatures $\left(T_{s}\right)$.

Additionally, Figure $7 \mathrm{~b}$ shows how the melting enthalpy of each phase changes when the $\mathrm{BS}_{45} \mathrm{BAz}_{55}{ }^{38}$ copolymer is self-nucleated. The enthalpy of the PBSrich phase varies as expected during the self-nucleation process. ${ }^{23,24}$ However, in the case of the PBAz-rich phase, the melting enthalpy sharply decreases when the sample goes from Domain I to Domain II, as clearly seen in Figure 7b. This is due to the antinucleation effect caused by the anticipated crystallization of the PBS-rich phase when it is self-nucleated. 
The $\mathrm{BS}_{45} \mathrm{BAz}_{55}{ }^{38}$ random copolymer forms a single phase melt (a fact that was also corroborated by SAXS, data not shown). Upon cooling from the melt, the PBSrich phase crystallizes first (at higher temperatures) in space filling spherulites (see PLOM micrographs below in Figure 15) where later (at lower temperatures) the PBAz-rich phase must accommodate inside their interlamellar spaces. If the PBS-rich phase is self-nucleated, it can crystallize to saturation at much higher temperatures well before the PBAz-rich phase starts to crystallize. The PBAz-rich phase antinucleation is therefore probably caused by topological restrictions created in the interlamellar domains of PBS-rich phase spherulites that are fully grown and impinged with one another.

On the other hand, when the $\mathrm{BS}_{45} \mathrm{BAz}_{55}{ }^{38}$ is not self-nucleated, upon cooling from the melt at $10^{\circ} \mathrm{C} / \mathrm{min}$, the PBS-rich phase cannot complete its crystallization before the PBAz-rich phase starts to crystallize and coincident crystallization or simultaneous crystallization develops.

\section{Wide Angle X-ray Scattering (WAXS)}

Samples for WAXS were prepared by melting films in a hot stage at identical conditions to the thermal protocol applied to the samples for the DSC measurements shown in Figure 1, except that they were cooled initially to $25^{\circ} \mathrm{C}$ at $10^{\circ} \mathrm{C} / \mathrm{min}$. Then they were loaded in the diffractometer chamber at $25^{\circ} \mathrm{C}$ and the WAXS patterns were measured, as shown in Figure 8. 


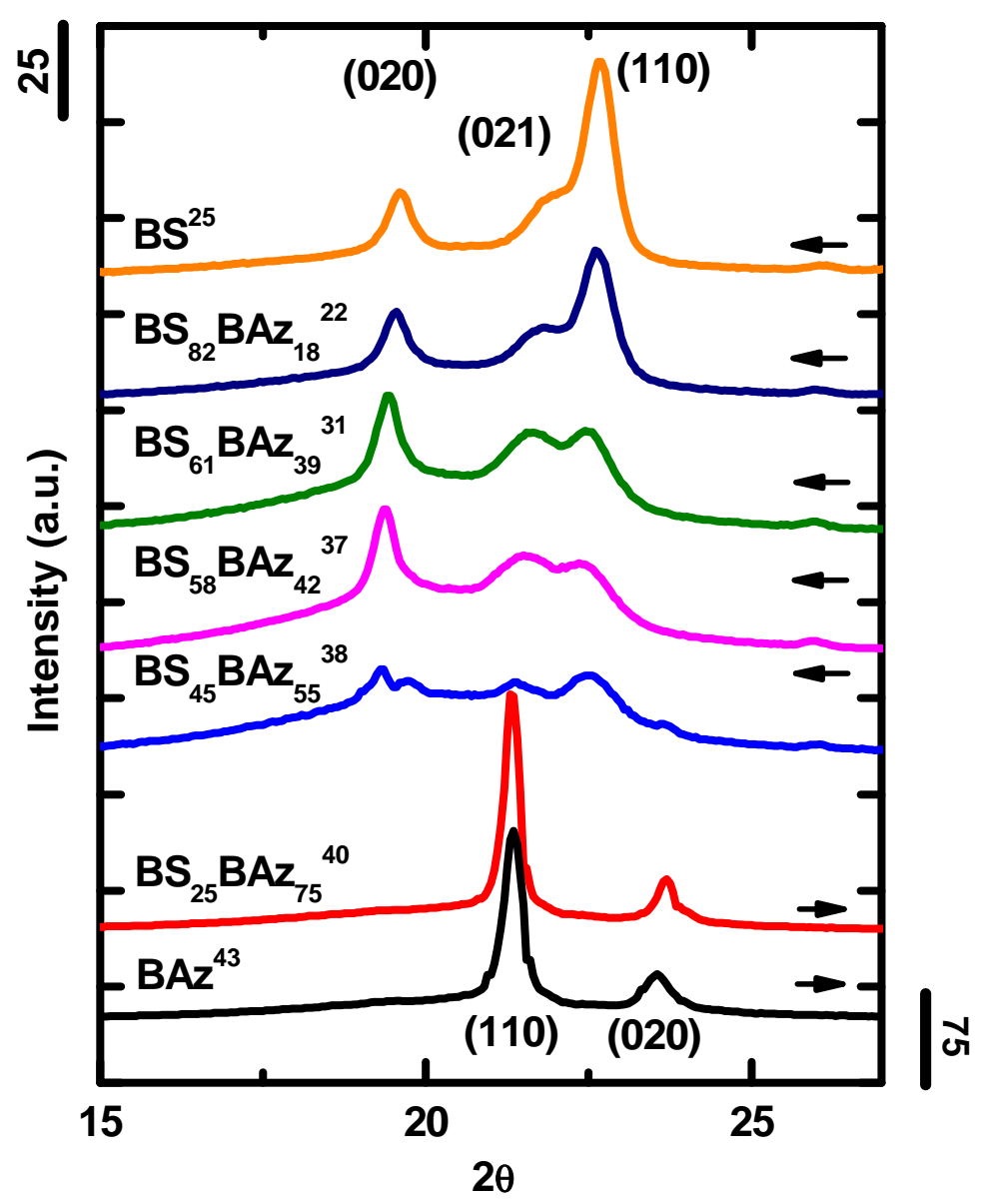

Figure 8. WAXS diffraction patterns for samples cooled from the melt at $10^{\circ} \mathrm{C} / \mathrm{min}$ to $25^{\circ} \mathrm{C}$. Measurements performed at $25^{\circ} \mathrm{C}$. See text.

Table 2 lists all the reflections and the $d$ spacings calculated by employing Bragg's law. The data reported in Table 2 for poly(butylene succinate) is consistent with the most common $\alpha$ form whose monoclinic unit cell dimensions are reported to $\mathrm{be}^{30-32}: \mathrm{a}=0.523 \mathrm{~nm}, \mathrm{~b}=0.908-0.912 \mathrm{~nm}, \mathrm{c}=1.079-1.090 \mathrm{~nm}$ and $\beta=123.9^{\circ}$. The most intense reflections for PBS appeared at $0.452,0.404$ and 0.392 and they can be indexed to (020), (021) and (110) planes, ${ }^{21,30-32}$ as indicated in Figure 8. In the case of PBAz, the crystalline unit cell has not been reported in the literature yet. A recent publication $^{21}$ has reported that fiber patterns from the melt drawn homopolymer are consistent with an orthorhombic unit cell with the following dimensions: $a=0.496 \mathrm{~nm}$, 
$\mathrm{b}=0.746 \mathrm{~nm}$ and $\mathrm{c}=3.65 \mathrm{~nm}$. Following their results, ${ }^{21}$ the most intense reflections (at $0.416 \mathrm{~nm}$ and $0.377 \mathrm{~nm}$ ) for PBAz have been tentatively indexed in Figure 8 as (110) and (020).

Table 2. Calculated diffraction spacings $(d)$ according to Bragg's law for the indicated samples at two different temperatures (see text).

\begin{tabular}{|c|c|c|c|c|}
\hline \multirow[b]{2}{*}{ Sample } & \multicolumn{2}{|c|}{$25^{\circ} \mathrm{C}$} & \multicolumn{2}{|c|}{$-30^{\circ} \mathrm{C}$} \\
\hline & $2 \theta$ & $d(\mathrm{~nm})$ & $2 \theta$ & $d(\mathrm{~nm})$ \\
\hline $\mathrm{BS}^{25}$ & $\begin{array}{l}19.60 \\
21.95 \\
22.55\end{array}$ & $\begin{array}{l}0.452 \\
0.404 \\
0.392\end{array}$ & $\begin{array}{l}19.70 \\
22.10 \\
22.80\end{array}$ & $\begin{array}{l}0.450 \\
0.402 \\
0.389\end{array}$ \\
\hline $\mathrm{BS}_{82} \mathrm{BAz}_{18}^{2}$ & $\begin{array}{l}19.55 \\
21.80 \\
22.60\end{array}$ & $\begin{array}{l}0.454 \\
0.407 \\
0.393\end{array}$ & $\begin{array}{l}19.65 \\
21.95 \\
22.80\end{array}$ & $\begin{array}{l}0.451 \\
0.404 \\
0.389\end{array}$ \\
\hline $\mathrm{BS}_{61} \mathrm{BAz}_{39}{ }^{3}$ & $\begin{array}{l}19.45 \\
21.65 \\
22.45 \\
\end{array}$ & $\begin{array}{l}0.456 \\
0.409 \\
0.396 \\
\end{array}$ & $\begin{array}{l}19.45 \\
21.70 \\
22.70 \\
\end{array}$ & $\begin{array}{l}0.456 \\
0.409 \\
0.391 \\
\end{array}$ \\
\hline $\mathrm{BS}_{58} \mathrm{BAz}_{42}{ }^{3}$ & $\begin{array}{l}19.40 \\
21.50 \\
22.35\end{array}$ & $\begin{array}{l}0.457 \\
0.413 \\
0.397\end{array}$ & $\begin{array}{l}19.40 \\
21.63 \\
21.65\end{array}$ & $\begin{array}{l}0.457 \\
0.410 \\
0.392\end{array}$ \\
\hline $\mathrm{BS}_{45} \mathrm{BAz}_{55}{ }^{3}$ & $\begin{array}{l}19.35 \\
19.75 \\
21.35 \\
22.45 \\
23.60\end{array}$ & $\begin{array}{l}0.458 \\
0.449 \\
0.416 \\
0.396 \\
0.377 \\
\end{array}$ & $\begin{array}{l}19.34 \\
20.00 \\
21.30 \\
21.75 \\
23.90 \\
\end{array}$ & $\begin{array}{l}0.458 \\
0.443 \\
0.417 \\
0.390 \\
0.371 \\
\end{array}$ \\
\hline $\mathrm{BS}_{25} \mathrm{BAz}_{75}{ }^{4}$ & $\begin{array}{l}21.30 \\
23.70 \\
\end{array}$ & $\begin{array}{l}0.417 \\
0.375 \\
\end{array}$ & $\begin{array}{l}21.45 \\
23.95 \\
\end{array}$ & $\begin{array}{l}0.414 \\
0.371 \\
\end{array}$ \\
\hline $\mathrm{BAz}^{43}$ & $\begin{array}{l}21.35 \\
23.55\end{array}$ & $\begin{array}{l}0.416 \\
0.377\end{array}$ & $\begin{array}{l}21.45 \\
23.80\end{array}$ & $\begin{array}{l}0.414 \\
0.373\end{array}$ \\
\hline
\end{tabular}

A careful examination of the WAXS patterns of Figure 8 indicates that at $25^{\circ} \mathrm{C}$, almost all samples contain only one type of crystal. The samples with more than 
$58 \%$ BS only display reflections that are consistent with a PBS type unit cell. BAz ${ }^{43}$ and $\mathrm{BS}_{25} \mathrm{BAz}_{75}{ }^{40}$ display a WAXS pattern that is characteristic of neat PBAz.

The only sample that contains characteristic reflections of both phases is $\mathrm{BS}_{45} \mathrm{BAz}_{55}{ }^{38}$, but the WAXS pattern is completely dominated by PBS reflections, since the reflections of the PBAz phase that can be detected have extremely small intensity values (at $0.416 \mathrm{~nm}$ and $0.377 \mathrm{~nm}$ as shown in Figure 8), indicating that the amount of PBAz like crystals is minimal at room temperature. This is consistent with the DSC curves presented in Figure $1 \mathrm{~b}$ and the data reported in Table 1 that indicates a $T_{m}$ value for the PBAz phase within the copolymer of $26.4^{\circ} \mathrm{C}$. Therefore at $25^{\circ} \mathrm{C}$, the temperature at which the WAXS patterns were taken, the PBAz phase was almost completely molten, especially since the temperature control within the WAXS chamber has a precision of $\pm 1^{\circ} \mathrm{C}$.

As the amount of PBAz increases in the copolymers from 18 to 55\%, the PBSrich phase exhibits a PBS like unit cell with $d$ spacings that slightly increase with PBAz content. The change in $d$ spacings with BAz content is plotted in Figure 9. The change is small but beyond experimental error and the increase in diffraction spacings with composition is systematic. Presumably, the crystal unit cells have to increase slightly their volume to accommodate the extra PBAz repeating units that co-exist with the PBS major component as a result of isodimorphism. Since the increase in $d$ spacings is small, this probably indicates that comonomer incorporation is also small but finite.

In the other extreme of compositions, where PBAz is the major phase, the $d$ spacings of PBAz do not exhibit a clear trend with composition, partly because of the limited number of samples (see Table 2). 


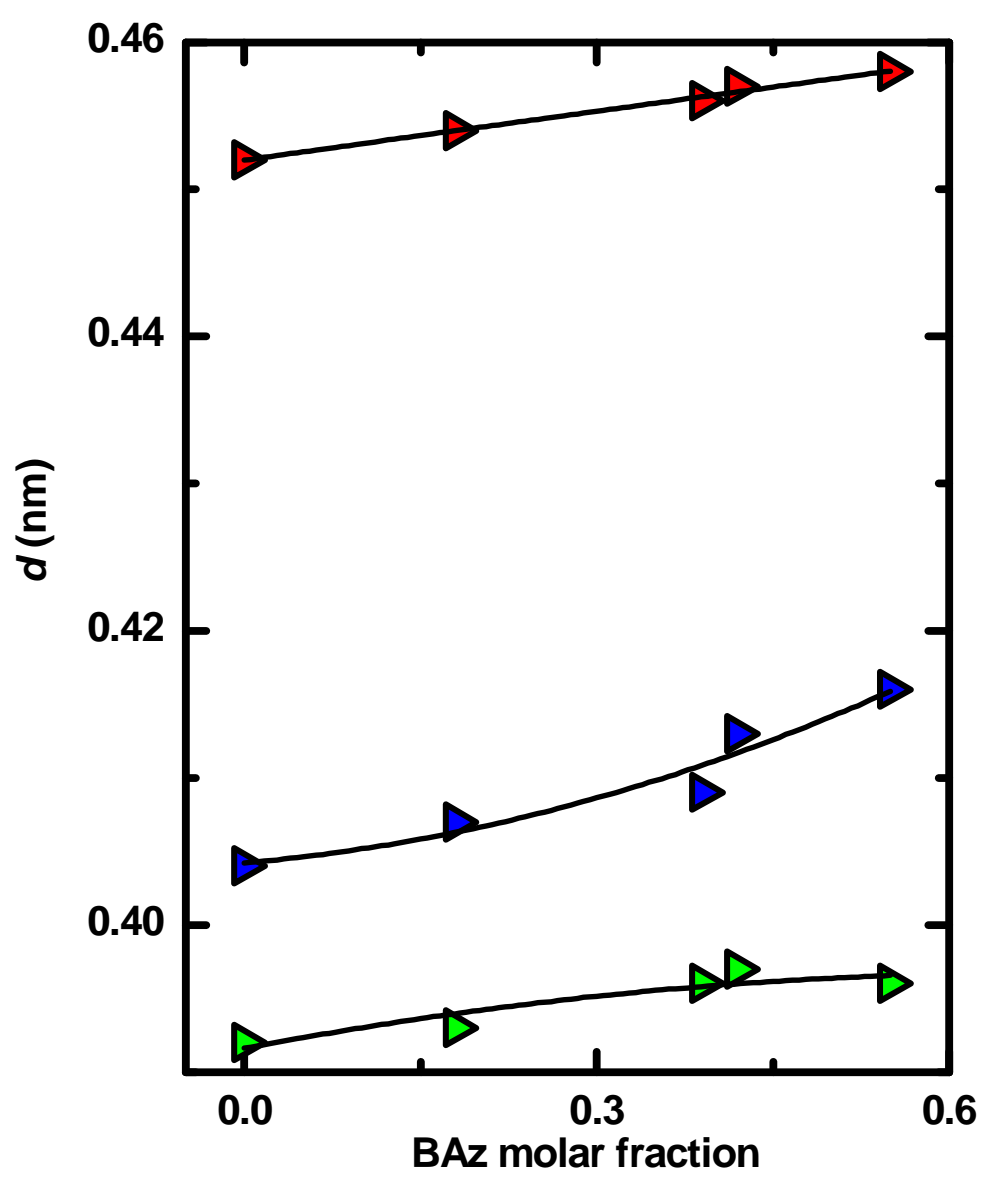

Figure 9. Experimental diffraction spacings $(d)$ for BS rich crystalline phase as a function of BAz molar content. From bottom to top, the series of data points joint together by arbitrary trend lines are for (110), (021) and (020) planes respectively of PBS (or PBS-rich) crystalline unit cell (green, blue and red symbols)

Figure 10 shows WAXS patterns that were measured for the same samples of Figure 8 after they were cooled down to $-30^{\circ} \mathrm{C}$ in order to promote the crystallization of the PBAz phase within the copolymers. As expected, in all samples, most $d$ spacings decreased (see Table 2) as compared to those measured at $25^{\circ} \mathrm{C}$, because of the effect of temperature on the unit cell volume. Besides these small changes in $d$ spacings, only one sample experienced a significant and large change in its WAXS pattern. This is the double crystalline $\mathrm{BS}_{45} \mathrm{BAz}_{55}{ }^{38}$ copolymer, for which the PBAzrich phase was able to crystallize upon cooling to $-30^{\circ} \mathrm{C}$ and now exhibits much more intense reflections (i.e., the (110) reflection appearing at $0.417 \mathrm{~nm}$ and the (200) 
reflection at $0.371 \mathrm{~nm}$ ) corresponding to the PBAz like unit cell, as compared to the WAXS pattern in Figure 8 (taken at $25^{\circ} \mathrm{C}$ ).

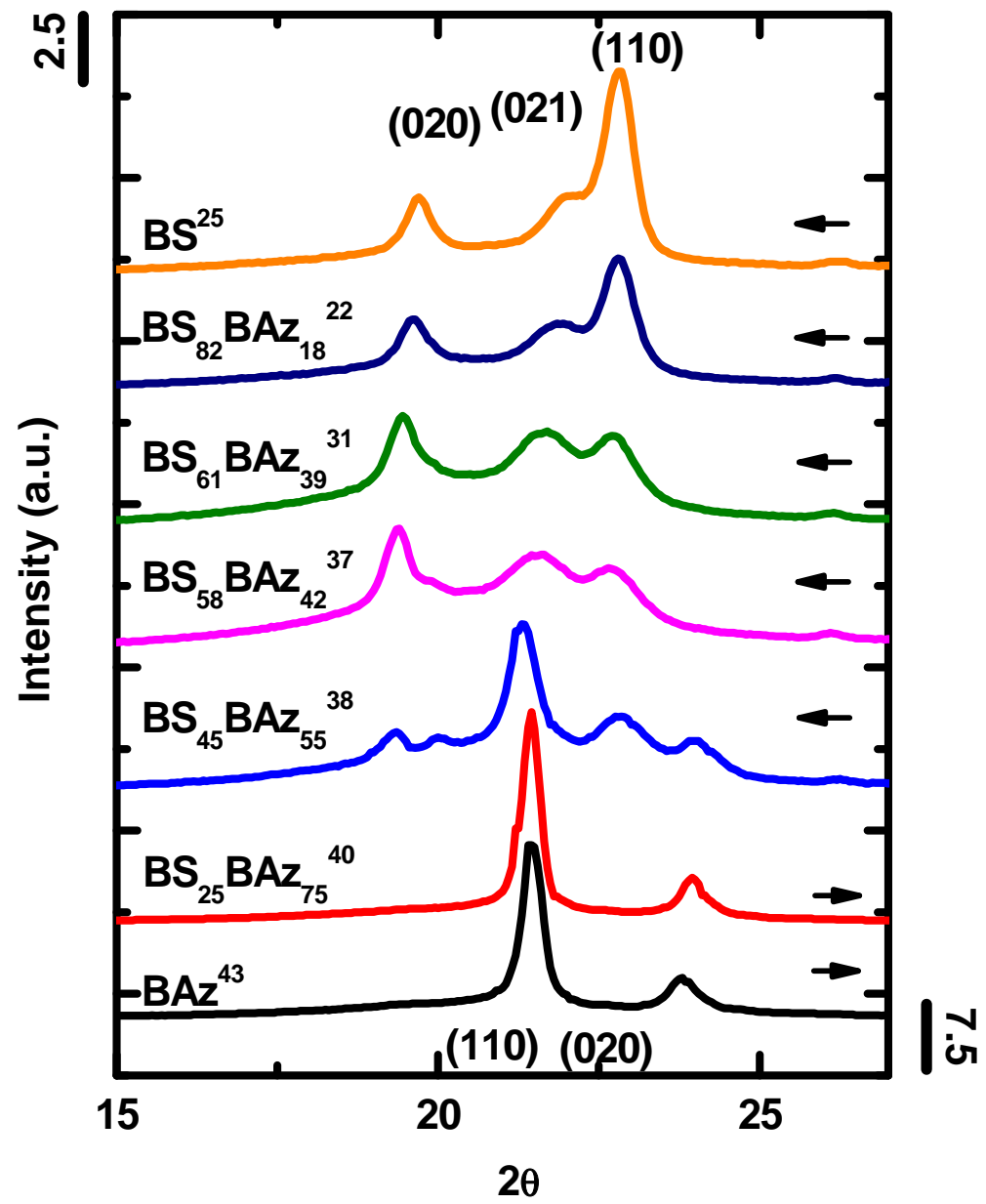

Figure 10. WAXS diffraction patterns taken at $-30^{\circ} \mathrm{C}$ for the indicated samples.

\section{Small Angle X-ray Scattering (SAXS)}

Analogous experiments to those performed by WAXS were conducted employing SAXS. The results for the measurements at $25^{\circ} \mathrm{C}$ and $-30^{\circ} \mathrm{C}$ are presented in Figure 11a and Figure 11b respectively, where the intensity is plotted as a function of the scattering vector $q$. Most samples exhibit a clear intense maximum that can be interpreted as the scattering caused by lamellar stacks. 
The long periods $\left(d^{*}\right)$ were estimated by equation 1 from Lorentz corrected plots $\left(I q^{2}\right.$ versus $\left.q\right)$ :

$$
\square^{*}=(2 \square) / \square \square \square \square \quad \text { (equation 1) }
$$

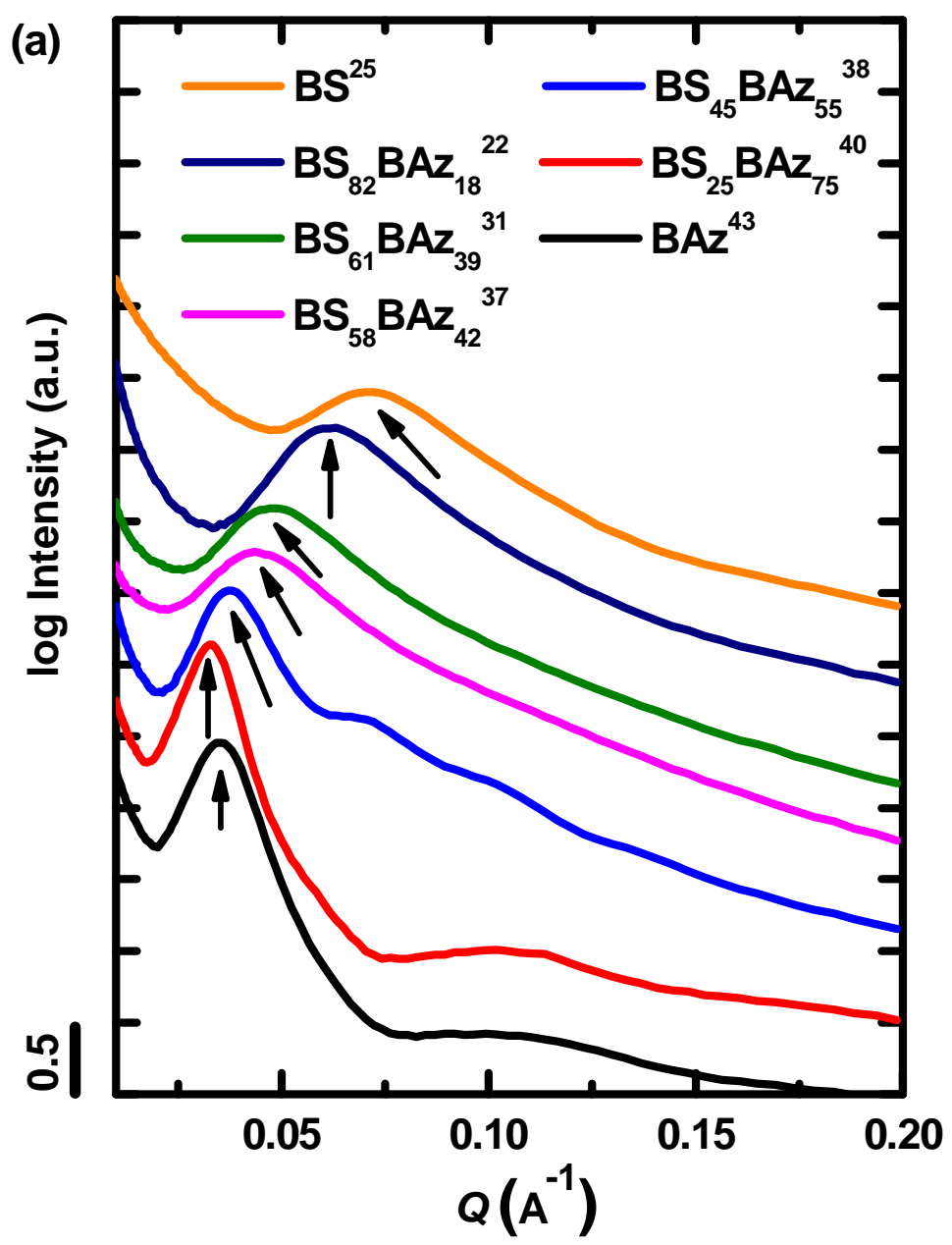




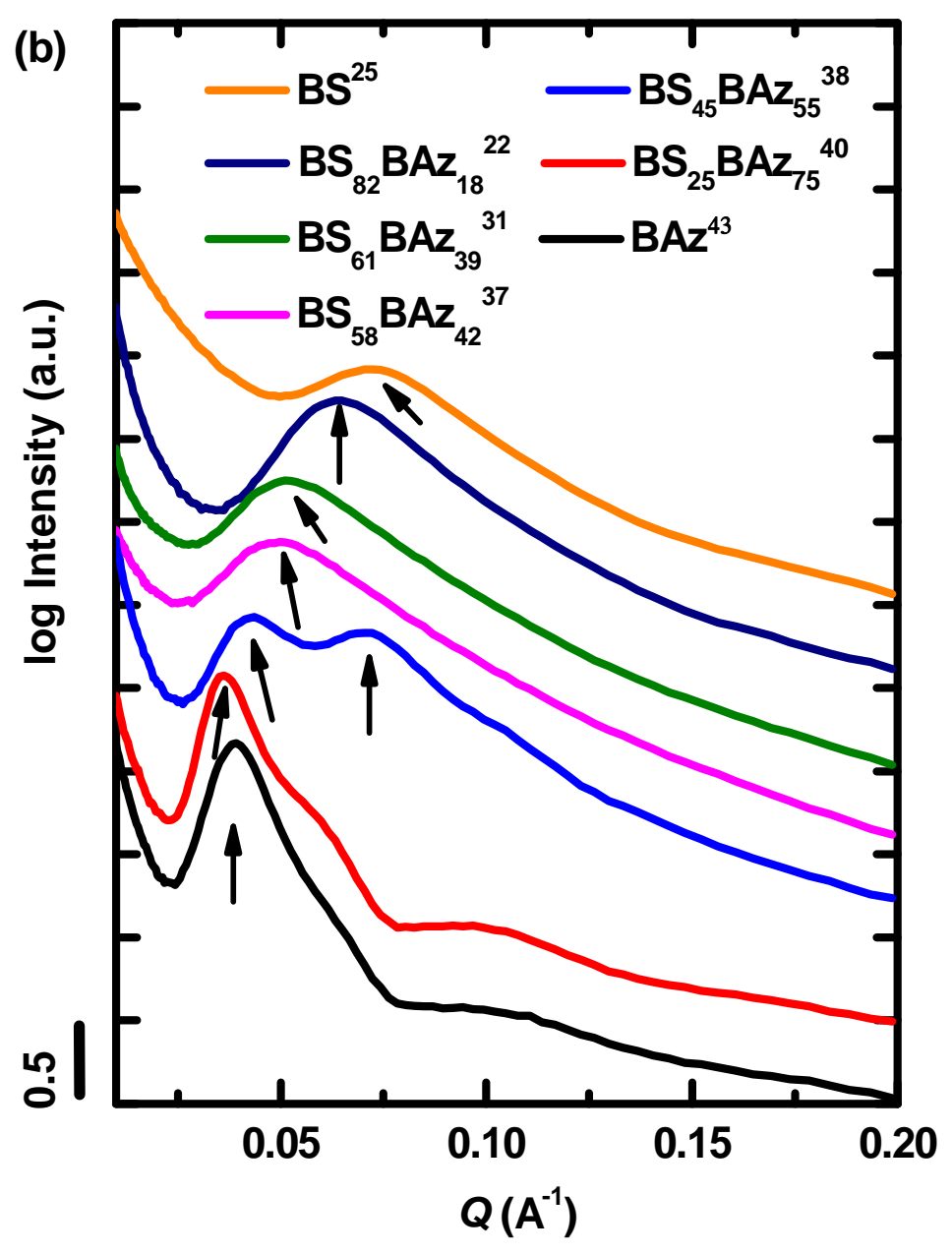

Figure 11. Intensity as a function of scattering vector for the indicated homopolymers and copolymers. Data taken at the following temperatures: (a) $25^{\circ} \mathrm{C}$ and (b) $-30^{\circ} \mathrm{C}$.

At $25^{\circ} \mathrm{C}$ our WAXS results have shown that only one type of crystal is present in the materials, i.e., either the PBS-rich phase or the PBAz-rich phase. Therefore, any subsidiary low intensity maxima located at higher $q$ values in Figure 11a as compared to the highest intensity peak can be explained as second or third order reflections arising from the lamellar structure, since their positions correspond to approximately $2 q_{\max }$ and $3 q_{\max }$ and the intensities are much lower compared to their first order peaks. 
When the SAXS patterns are measured at $-30^{\circ} \mathrm{C}$ (Figure $11 \mathrm{~b}$ ), the $\mathrm{BS}_{45} \mathrm{BAz}_{55}{ }^{38}$ copolymer exhibits a remarkable change as a result of the crystallization of both PBSrich and PBAz-rich phases. The SAXS pattern taken at $-30^{\circ} \mathrm{C}$ exhibits two scattering peaks with almost equivalent intensity indicating that the material is constituted by two types of lamellar stacks with enough density contrast to be able to individually produce small angle scattering at discrete $q$ values. The peak located at lower $q$ values can be assigned to the long period of the PBS-rich lamellar stacks (see Figure 12 below) while that at higher $q$ values to the PBAz-rich phase lamellar long period. No significant changes were observed for the other samples at $-30^{\circ} \mathrm{C}$ (when compared with $25^{\circ} \mathrm{C}$ ) except relatively small changes in $d$ values.

Figure 12 shows a plot of the measured long periods as a function of copolymer composition. The long periods were obtained from the data presented in Figure 11 and also from one additional experiment that was performed to evaluate reversibility and reproducibility. After the samples were cooled to $-30^{\circ} \mathrm{C}$, they were heated back to $25^{\circ} \mathrm{C}$ and re-measured, and both data sets obtained at $25^{\circ} \mathrm{C}$ were equivalent within experimental errors as shown in Figure 12 (labeled $25^{\circ} \mathrm{C}$ and $25^{\circ} \mathrm{C}$, $2^{\text {nd }}$ heating). 


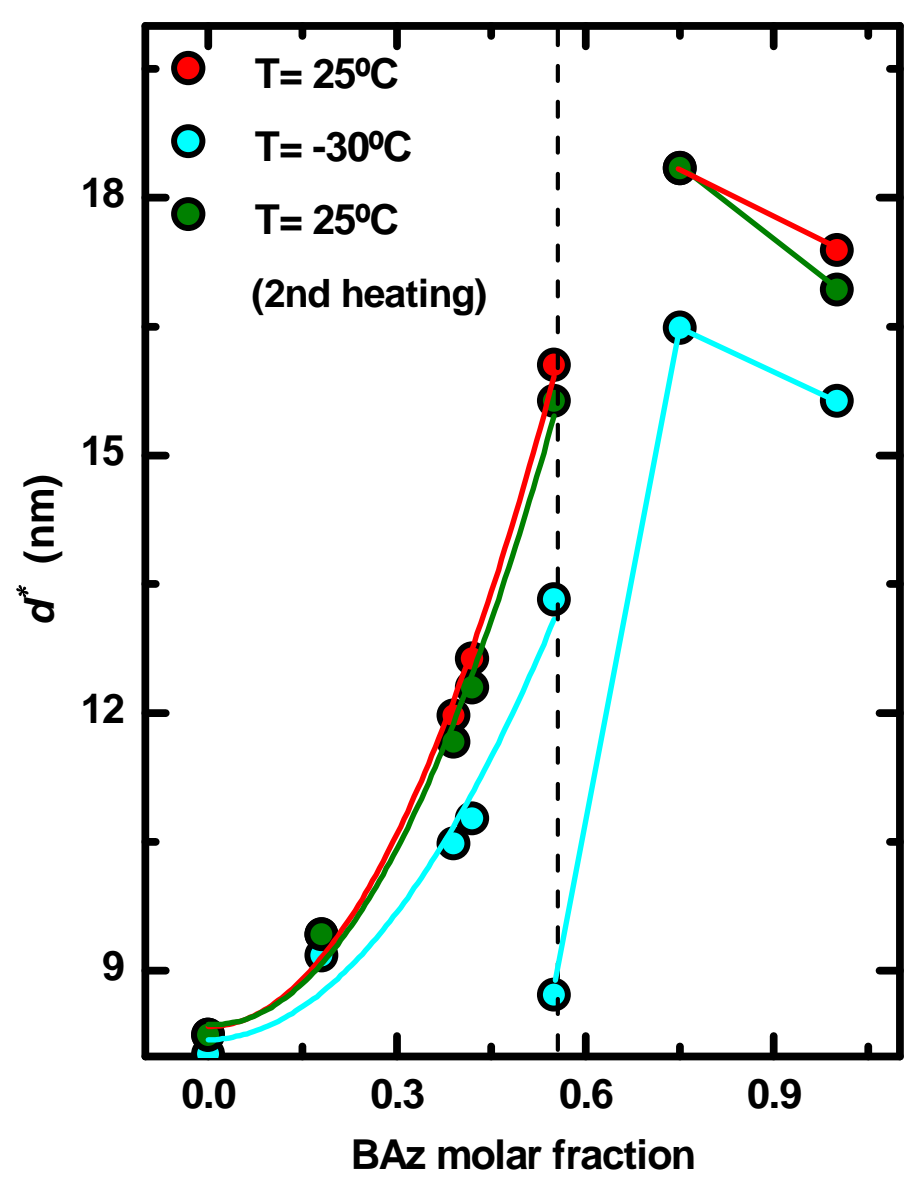

Figure 12. Long periods $\left(d^{*}\right)$ obtained by SAXS as a function of copolymer composition (expressed as BAz molar fraction). Arbitrary lines have been drawn joining the data points to guide the eye.

SAXS data for this type of copolymers had not been reported in the literature as far as the authors are aware. It is interesting to note that $d^{*}$ spacings strongly depend on composition (Figure 12). A vertical line has been drawn at the composition corresponding to the $\mathrm{BS}_{45} \mathrm{BAz}_{55}{ }^{38}$ copolymer (dash line in Figure 12), which should be very close to the eutectic point of the system. To the left of the eutectic all data points correspond to $d^{*}$ spacings of the PBS-rich phase. To the right of the eutectic the data points correspond to the $d^{*}$ spacings of the PBAz-rich phase. The lines that go through the data points have been drawn arbitrarily to guide the eye. 
Let us consider in Figure 12 the long period values to the left of the eutectic point, i.e., for PBS and PBS-rich crystalline phases. PBS crystallizes forming spherulites that contain lamellar stacks with an average long period of approximately $8.5 \mathrm{~nm}$. For the PBS-rich phase, both at $25^{\circ} \mathrm{C}$ and at $-30^{\circ} \mathrm{C}$, spherulites are also formed (see below) and the lamellar long period increases with BAz content in the copolymers to values as high as $13.5-16.3 \mathrm{~nm}$. This is a remarkable behavior indicating that the incorporation of PBAz both in the crystalline unit cell (Figure 8) and in the amorphous regions of the PBS-rich interlamellar zones has a synergistic effect on the morphology at the lamellar level. Increases in long period indicate changes in lamellar thickness and/or interlamellar regions (amorphous intervening layer). The changes in the lamellar thickness are estimated below.

In the case of the PBAz-rich phase the behavior shown in Figure 12 is very peculiar in two aspects: (a) $d^{*}$ increases when $25 \%$ BS is included in the copolymer, a behavior that may be related to the incorporation of some BS repeating units in the PBAz-rich phase lamellae (a similar case to that described above for the PBS-rich copolymers). (b) At $-30^{\circ} \mathrm{C}$, the long period of the PBAz-rich phase experiences a dramatic decrease when $45 \% \mathrm{BS}$ is incorporated in the copolymer. This reduction in long period is caused by the previous crystallization of the PBS-rich phase within the $\mathrm{BS}_{45} \mathrm{BAz}_{55}{ }^{38}$ copolymer. When the sample was originally cooled from the melt, the PBS phase crystallized forming space filling spherulites (see Figure 15 below) that constitute a template for the copolymer morphology. Upon further cooling to $-30^{\circ} \mathrm{C}$, the PBAz-rich phase had to crystallize within the confined interlamellar regions of the previously obtained PBS-rich phase spherulites. 


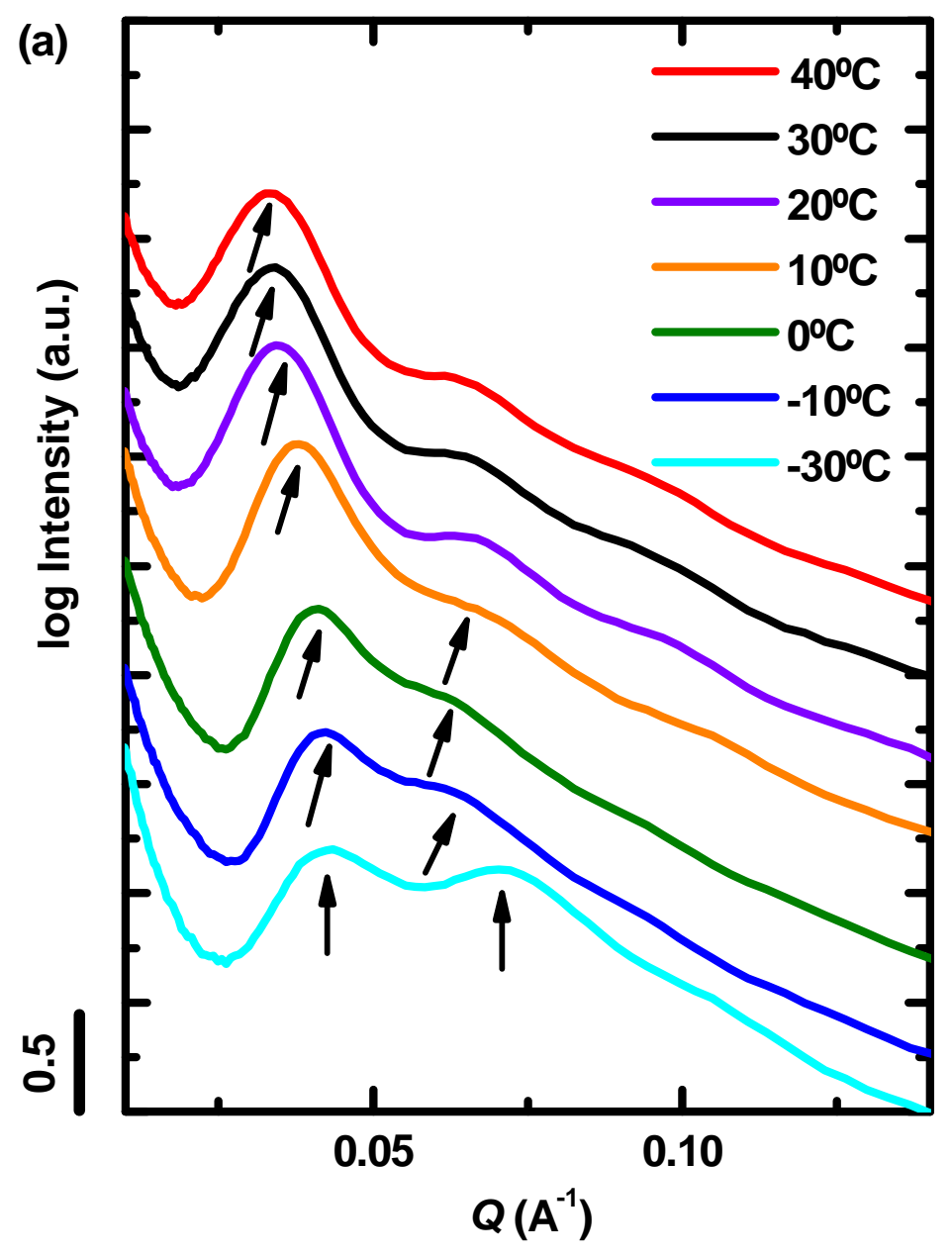




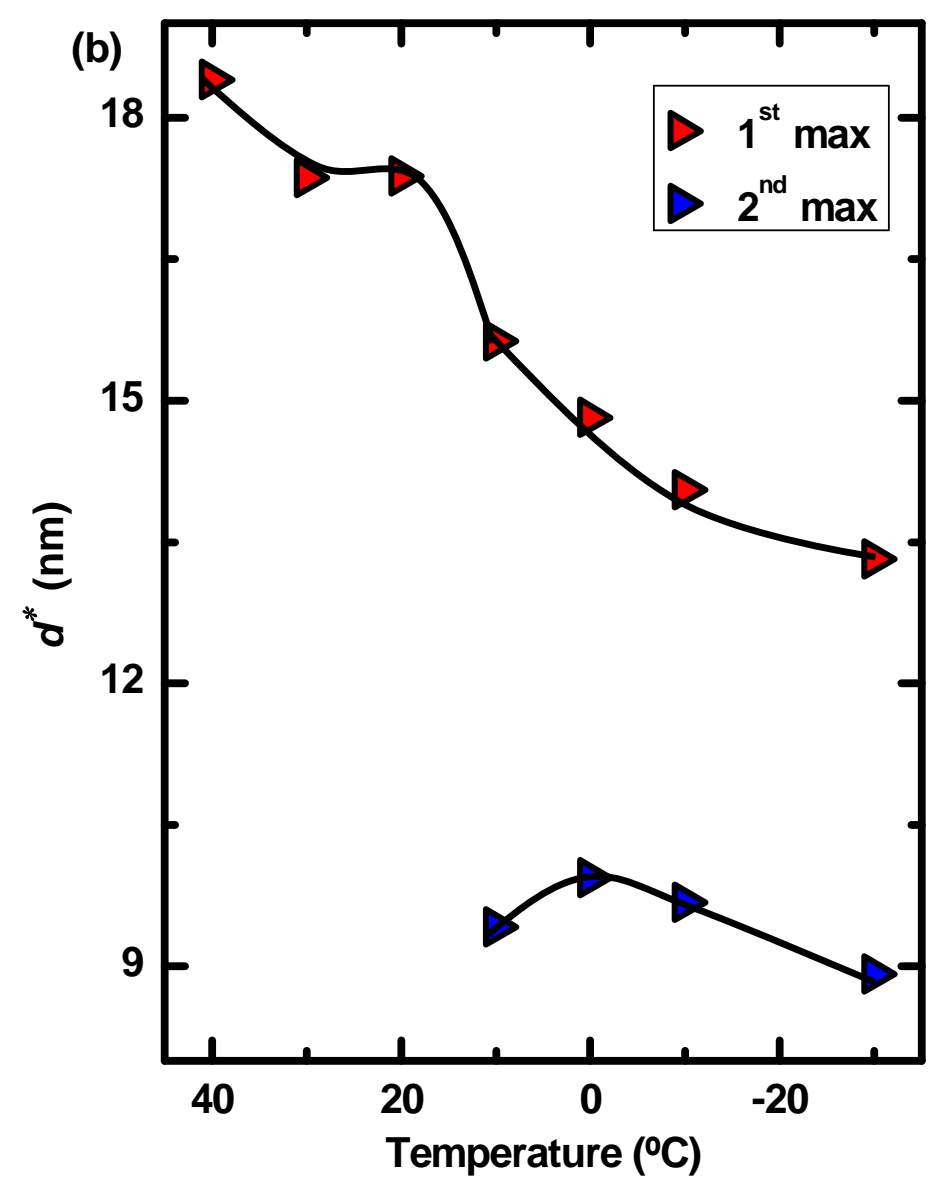

Figure 13. (a) Intensity versus scattering vector for the $\mathrm{BS}_{45} \mathrm{BAz}_{55}{ }^{38}$ copolymer as it is cooled from $40^{\circ} \mathrm{C}$ down to $-30^{\circ} \mathrm{C}$. (b) Long spacings $\left(d^{*}\right)$ calculated from SAXS data presented in (a) as a function of temperature. Arbitrary lines have been drawn joining the data points to guide the eye.

The changes in the SAXS pattern of the $\mathrm{BS}_{45} \mathrm{BAz}_{55}{ }^{38}$ copolymer while it transforms from a single semi-crystalline material (i.e., containing only PBS-rich phase lamellae) to a double crystalline material (i.e., containing both PBS-rich and PBAz-rich phase lamellae) can be clearly observed in Figure 13a. In this figure, the sample was first heated from $-30^{\circ} \mathrm{C}$ to $40^{\circ} \mathrm{C}$ in order to fully melt the PBAz-rich crystalline phase. Then SAXS patterns were taken at increasingly lower temperatures, as the sample was cooled down as shown in Figure 13a. 
The SAXS patterns at 40,30 and $20^{\circ} \mathrm{C}$ do not exhibit significant changes (see Figure 13a) since only the PBS-rich crystalline lamellar stacks are present (as confirmed by WAXS). At $10^{\circ} \mathrm{C}$, the PBAz-rich phase starts to crystallize and the SAXS patterns progressively evolve. Such evolution can be seen in Figure 13b where the change in long periods as a function of temperature is represented. The first SAXS maxima correspond to the long period of the PBS-rich phase, which remains approximately constant until $20^{\circ} \mathrm{C}$. However, as the PBAz-rich phase starts to crystallize at temperatures below $20^{\circ} \mathrm{C}$ (and a second maximum develops at higher $q$ values), the long spacing of the PBS-rich phase decreases (see Figure 13b, first SAXS maximum data). Such a decrease indicates that extensive lamellar rearrangement occurs within the spherulites (together with the density increase that accompanies crystallization) for the two types of lamellae to co-exist inside the mixed spherulites formed by this isodimorphic random copolymer.

Perfect interlamellar stacking (or inter-digitation, where alternating lamellae of each phase are stack on one another) would not be consistent with the values obtained at $-30^{\circ} \mathrm{C}$ for the two characteristic long periods of each crystalline phase: approximately 13.3 and $8.5 \mathrm{~nm}$ (Figure 13b). The results may stem from average long periods of a complicated interfibrillar structure that could be schematically represented in the model shown in Figure 14. Similar structures have been observed in crystalline/crystalline binary blends. ${ }^{33-40}$ 


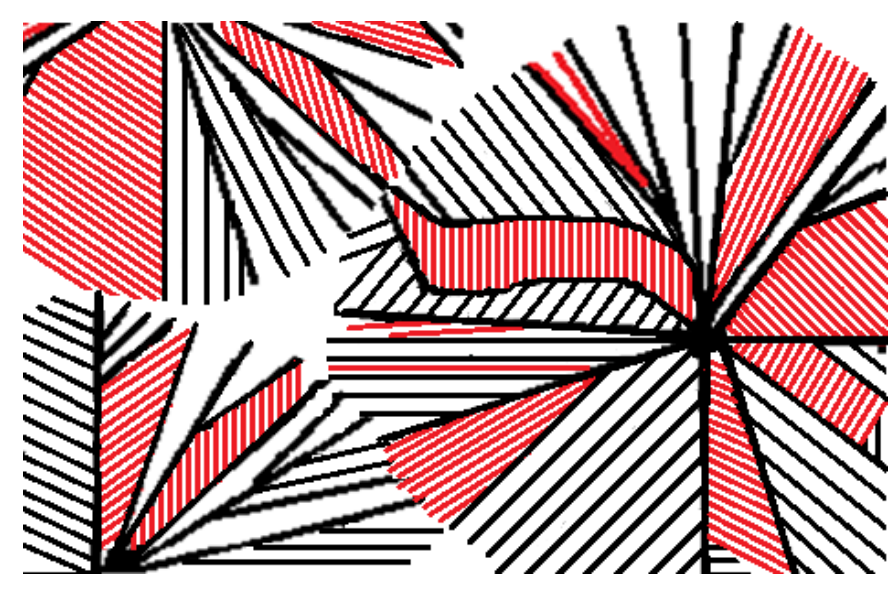

Figure 14. A schematic (not to scale) model of the possible double crystalline lamellar stacking morphology inside mixed spherulites of the $\mathrm{BS}_{45} \mathrm{BAz}_{55}{ }^{38}$ copolymer at $-30^{\circ} \mathrm{C}$. The black lines indicate PBS-rich lamellae while the red lines correspond to PBAz lamellae.

Calculation of the lamellar thickness requires the knowledge of the crystallinity degree of each phase. The calculation of the lamellar thickness, $l$, could be performed employing the following approximation:

$$
\square=\square^{*} \square_{\square} \quad \text { (equation 2) }
$$

where $x_{v}$ is the crystalline volume fraction that can be estimated from the following equations:

$$
\begin{array}{ll}
\square_{\square} & =\left(\square_{\square} \square\right) / \square_{\square} \quad \text { (equation 3) } \\
\square_{\square}=\frac{\Delta \square_{\square}}{\Delta \square_{\square(100 \%) \square}} \quad \text { (equation 4) }
\end{array}
$$

where $\square_{\square}$ is the mass fraction of crystals, $\rho$ is the experimentally determined density of the sample (at $25^{\circ} \mathrm{C}$ ) and $\rho_{c}$ the density of a $100 \%$ crystalline sample. 
Table 3. Density, normalized enthalpy of crystallization, mass and volume crystalline fractions, long period and lamellar thickness values.

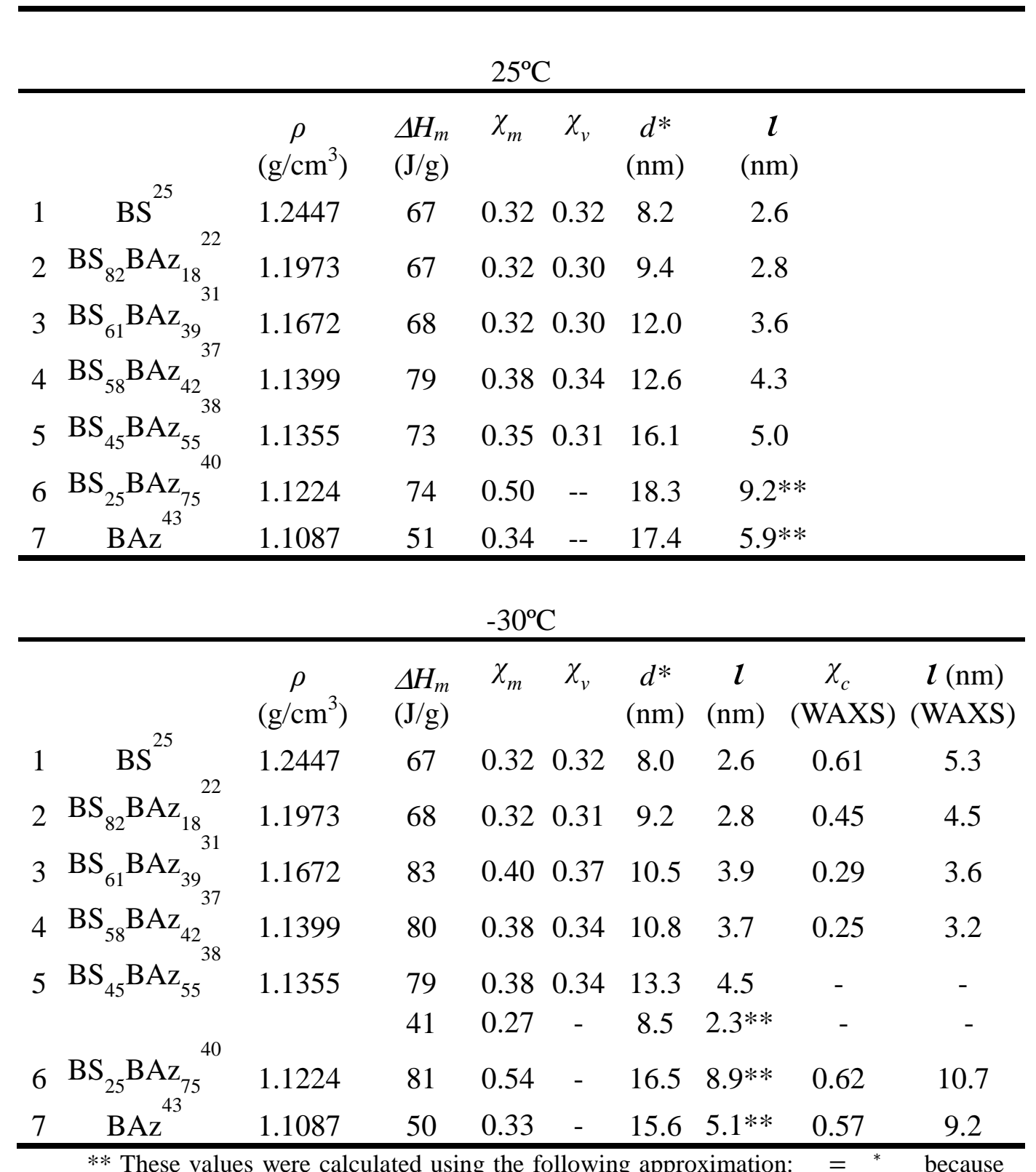
is unknown for PBAz. The density of the samples was measured at $25^{\circ} \mathrm{C}$ and was also used for the calculations at $-30^{\circ} \mathrm{C}$ (although a change in density must have occurred).

The mass fraction of crystals can be calculated from the enthalpy of fusion of the phase under consideration $\left(\Delta H_{m}\right)$, the enthalpy of fusion of a $100 \%$ crystalline sample and the weight fraction of the phase under consideration $(W)$ employing equation 4 . The density of the samples at $25^{\circ} \mathrm{C}$ was determined experimentally and the results are listed in Table 3 . The crystalline density of PBS can be found in the 
literature as well as its $\Delta H_{m(100 \%)}$ value: $\Delta H_{m(100 \%)}=210 \mathrm{~J} / \mathrm{g}{ }^{41}$ and $\rho_{c}=1.26 \mathrm{~g} / \mathrm{cm}^{3} .42$ A value for $\Delta H_{m(100 \%)}$ of $150 \mathrm{~J} / \mathrm{g}$ has been reported ${ }^{43}$ for PBAz. However, since the crystalline structure of PBAz has not been solved, its crystalline density is unknown.

Table 3 reports the calculations of the lamellar thickness based on DSC and density determinations at both 25 and $-30^{\circ} \mathrm{C}$. The calculated values exhibit, for the PBS phase, an increasing trend in $l$ as the BAz content in the copolymers increase. The values increase from approximately $2.6 \mathrm{~nm}$ for PBS up to $5.0 \mathrm{~nm}$ for the PBSrich phase within the $\mathrm{BS}_{45} \mathrm{BAz}_{55}{ }^{38}$ copolymer. Since the crystallinity degrees determined by DSC do not vary much (less than 15\%) with copolymer composition for the PBS-rich phase, the lamellar thickness variation follows the trend exhibited by the long period in Figure 12 when the amount of PBAz is increased (left side of the eutectic).

An attempt was also made to calculate the crystallinity degrees employing WAXS data taken at $-30^{\circ} \mathrm{C}$. Following the method of Krimm and Tobolsky, ${ }^{44}$ the crystallinity index was calculated by deconvolution of amorphous and crystalline scattering peaks. The values of $l$ in that case exhibit a different trend with composition compared with those calculated by DSC (see Table 3). The striking results manifest the complicated structure of the PBS-ran-PBAz copolymers. It is possible that the thermodynamic parameters of these materials are composition dependent, such as equilibrium melting temperature, enthalpy of fusion for $100 \%$ crystallinity, and folded surface free energy. Therefore, some well-established regulations may not be applicable in these materials. 
Polarized Light Optical Microscopy (PLOM) and AFM examination of the $\mathrm{BS}_{45} \mathrm{BA} z_{55}^{38}$ copolymer

$\mathrm{BS}_{45} \mathrm{BAz}_{55}{ }^{38}$ is the only copolymer that developed a double crystalline morphology, as demonstrated by the results obtained by DSC, WAXS and SAXS and discussed above. This isodimorphic copolymer features a morphology that is somewhat similar to that exhibited by double crystalline diblock copolymers that are miscible or in the weak segregation regime. ${ }^{29,45,46}$ Upon cooling from the melt in a PLOM hot stage at $10^{\circ} \mathrm{C} / \mathrm{min}$, the first phase capable of crystallization is the PBS-rich phase.

Figure 15 shows PBS-rich phase spherulites after the sample was cooled from the melt and held at $35^{\circ} \mathrm{C}$ for $38 \mathrm{~min}$. This phase develops negative spherulitic superstructural aggregates that resemble those of PBS (see inset in Figure 5) but exhibit irregular edges (not perfectly circular). At this temperature the PBAz-rich phase is in the melt. If the sample is held at this temperature for a long time (a couple of days for instance), the whole field fills with impinged PBS-rich phase spherulites that contain within them two phases: (a) A crystalline phase constituted by PBS-rich phase radial lamellae, where mostly BS repeating units are organized in stacked unit cells with their c axis tangentially arranged, and a certain proportion of BAz units that have been able to enter the PBS crystalline unit cells; and (b) An amorphous phase constituted by copolymer chains with BAz and BS repeating units in the amorphous intra-spherulitic regions. 

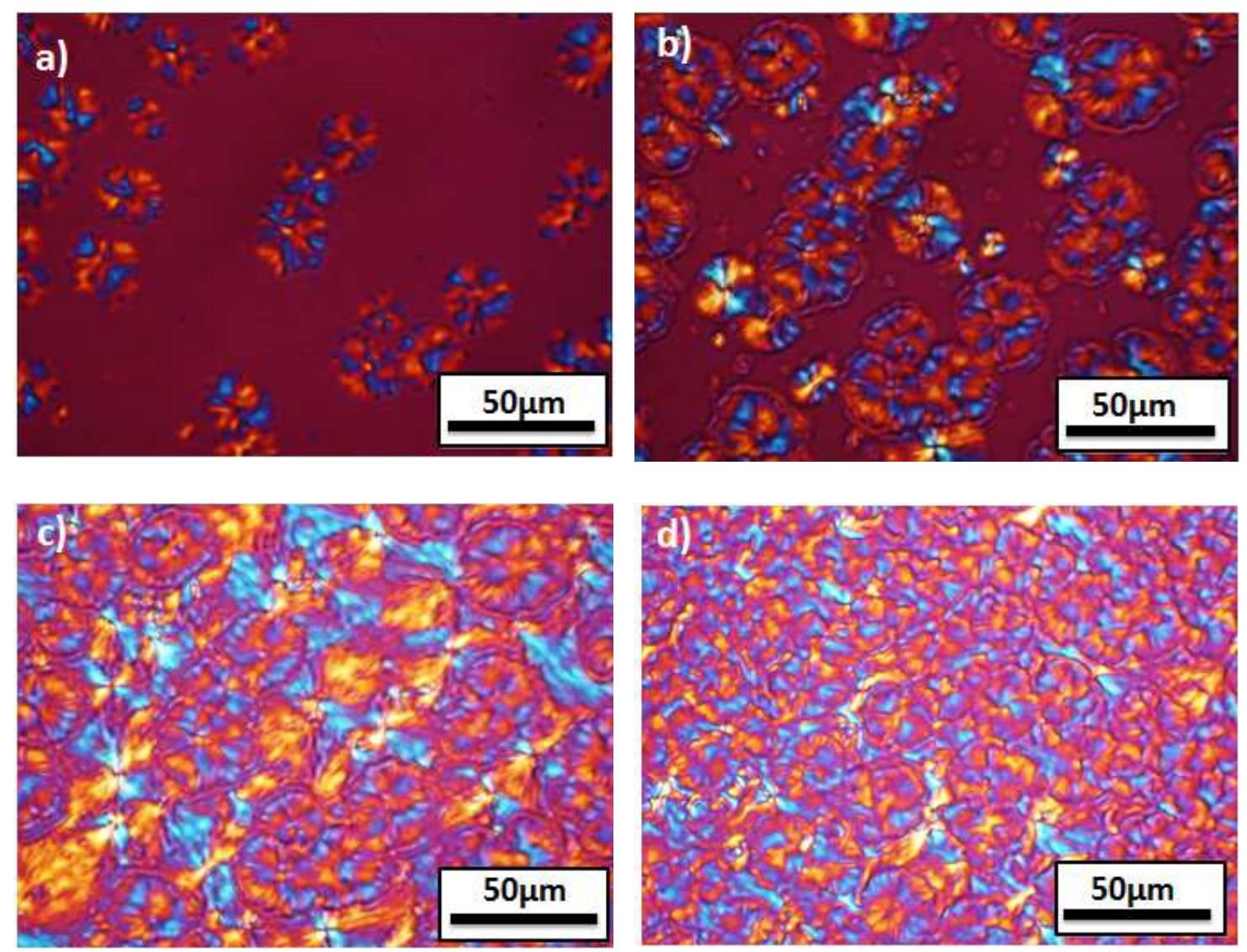

Figure 15. Polarized Light Optical Micrographs of the $\mathrm{BS}_{45} \mathrm{BAz}_{55}{ }^{38}$ copolymer: (a) the sample was cooled from the melt and held at $35^{\circ} \mathrm{C}$ for $38 \mathrm{~min}$, (b) micrograph taken after the sample in (a) was quenched rapidly from $35^{\circ} \mathrm{C}$ down to $8^{\circ} \mathrm{C}$, (c) after 2 min at $8^{\circ} \mathrm{C}$ and (d) the sample was reheated to $25^{\circ} \mathrm{C}$. See text.

Figures $15 \mathrm{~b}-\mathrm{c}$ show the result of quenching the sample shown in Figure 15a from $35^{\circ} \mathrm{C}$ down to $8^{\circ} \mathrm{C}$, a temperature at which the $\mathrm{BAZ}$ rich phase crystallizes rapidly. The remaining PBS amorphous phase can also crystallize at $8^{\circ} \mathrm{C}$. As a result of enhanced nucleation at this lower temperature, a higher number of spherulites can be seen. Figure $15 \mathrm{c}$ is a micrograph taken after just 2 min at $8^{\circ} \mathrm{C}$ and the microscope field is already filled with impinging mixed spherulites that contain lamellar crystals of both phases, as indicated schematically in Figure 14. Figure $15 \mathrm{~d}$ shows the morphology after the sample was heated back up to $25^{\circ} \mathrm{C}$ to melt the PBAz-rich phase 
crystals. The field remains full with PBS-rich phase spherulites as expected since the molten PBAz-rich phase is within the intra-spherulitic regions of the PBS phase.
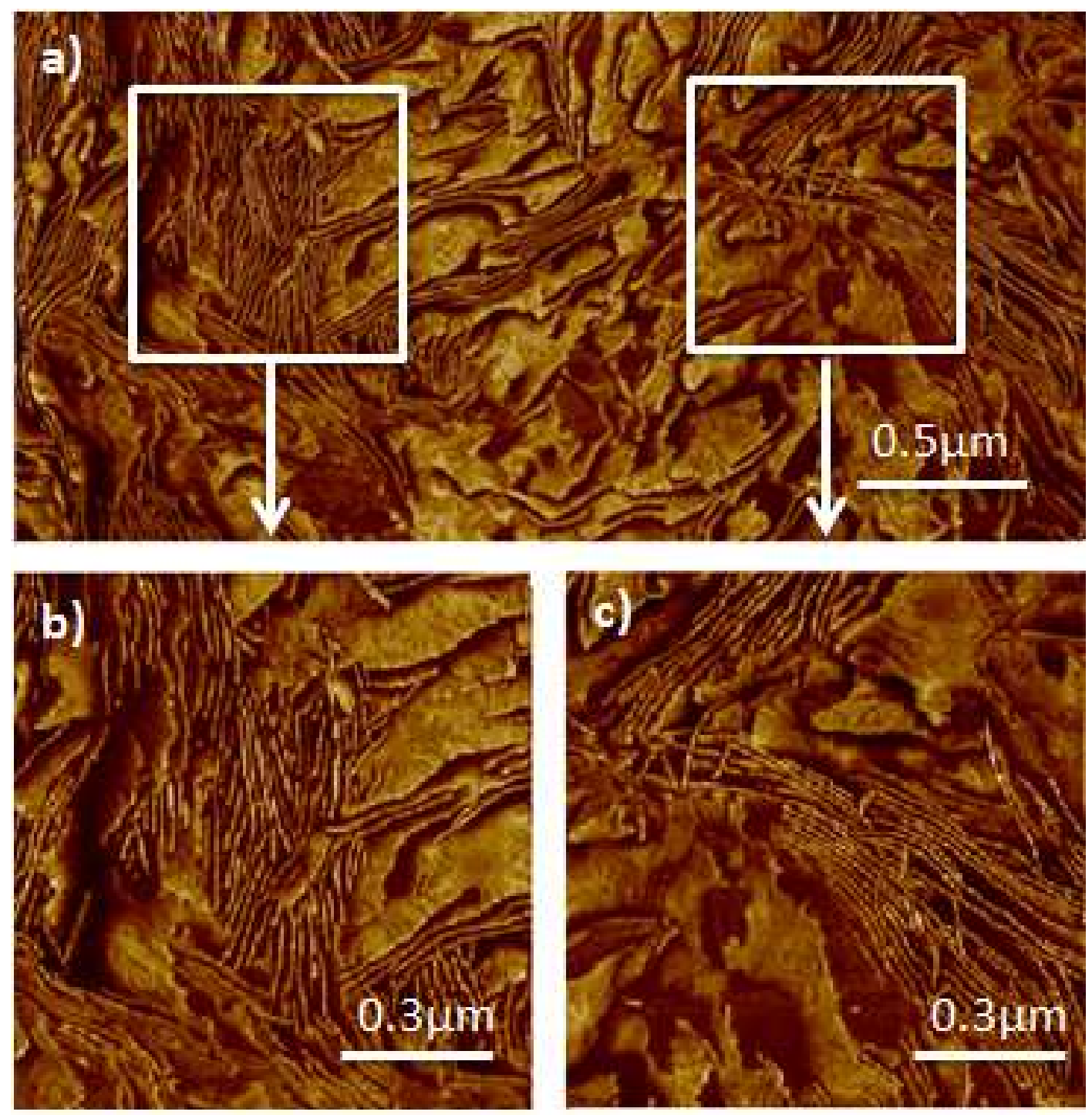

Figure 16. AFM phase contrast micrographs for a spin coated $\mathrm{BS}_{45} \mathrm{BAz}_{55}{ }^{38}$ copolymer sample observed at $25^{\circ} \mathrm{C}$.

A sample of the same $\mathrm{BS}_{45} \mathrm{BAz}_{55}{ }^{38}$ copolymer was spin coated onto a mica substrate (see experimental part). The sample was then isothermally crystallized at $35^{\circ} \mathrm{C}$ for $15.5 \mathrm{~h}$ and then cooled to $25^{\circ} \mathrm{C}$. The sample was observed at $25^{\circ} \mathrm{C}$ under an 
AFM microscope. At room temperature we can consider that only the PBS-rich phase is present, since the PBAz-rich phase is mostly in the melt state. Figure 16a shows a panoramic view of the crystalline texture of the sample obtained in the phase contrast mode. The image shows edge on and flat on PBS-rich phase lamellae embedded in an amorphous matrix where the potentially crystallizable (at much lower temperatures) PBAz-rich phase is in the molten state. Taking advantage of the regions of the sample where many edge on lamellae are located (see Figures $16 \mathrm{~b}$ and 16c which represent a close up of two areas within Figure 16a), measurements were taken of at least 50 representative lamellae and their long period and lamellar thickness were averaged. The values obtained were: $d^{*}=15.2 \pm 0.3 \mathrm{~nm}$ and $l=5.2 \pm 0.8 \mathrm{~nm}$. These values are in excellent agreement with the values obtained by SAXS at $25^{\circ} \mathrm{C}$ where a $d^{*}$ value of $16.1 \mathrm{~nm}$ was measured and an $l$ value of $5.0 \mathrm{~nm}$ calculated (see Table 3). Our AFM microscope cannot cool below room temperature and we were not able to see the crystallization of the PBAz-rich phase by AFM. However, the evidence by PLOM and SAXS are consistent with the schematic picture shown in Figure 14.

\section{Conclusions}

Regulating the composition of isodimorphic random copolymers is a valuable tool to tailor their properties in an unusually wide temperature range. The melting temperature of the materials goes through a eutectic point when plotted as a function of composition. WAXS measurements demonstrated that apart from one composition around the eutectic point, all of the other random copolyesters were characterized by the sole crystallization of the most abundant component. Our WAXS results showed that small but reproducible changes are produced in the crystalline unit cell of the dominant crystalline phase upon inclusion of comonomer units. 
On the other hand, very large changes were observed in terms of crystallization and melting temperatures as well as in the superstructural and lamellar morphology when PBAz is incorporated randomly into PBS macromolecular chains. Lamellar spacings and lamellar thicknesses were found to be strongly dependent on copolymer composition by SAXS determinations.

In the interesting case of the double crystalline copolymer with a composition close to the eutectic point $\left(\mathrm{BS}_{45} \mathrm{BAz}_{55}{ }^{38}\right)$, coincident crystallization occurred when the material was cooled from the melt at $10^{\circ} \mathrm{C} / \mathrm{min}$. After self-nucleation of the PBS-rich crystalline phase, the separate crystallization of both phases can be achieved.

Considering the results from WAXS, SAXS, PLOM and AFM for the double crystalline $\mathrm{BS}_{45} \mathrm{BAz}_{55}{ }^{38}$ copolymer, a clear morphological picture emerged. When the material is cooled from the melt, PBS-rich space filling spherulites are formed and they produce a template for the copolymer morphology. These spherulites are constituted by radially growing lamellae of PBS-rich crystals with amorphous intervening layers of PBAz-rich phase. Upon further cooling from the melt, the PBAz-rich phase crystallizes forming much smaller lamellae that are stacked within the intra-spherulitic regions of the large PBS-rich spherulites. The two types of lamellae co-exist within these unusual mixed spherulites and have enough contrast and different spacings to produce two well defined equally intensive SAXS maxima.

\section{Acknowledgements}

We would like to thank the Basque Country Government for the financial support received through SAIOTEK project S-PE13UN051. AJM acknowledges financial support from the Basque Country Consolidated Rheology Group at Polymat (UPV/EHU) for which he would also like to thank Antxon Santamaría and María 
Eugenia Muñoz. R.M. and P.D. are grateful to Région Wallonne and European Commission for the financial support in the frame of SINOPLISS-POLYEST project and OPTI²MAT program of excellence. AA acknowledges support from the projects IT-654-13 (GV) and MAT2012-31088 (Ministerio de Economía y Competitividad). GML acknowledges the financial support from the National Natural Science Foundation of China (NSFC, Grant No. 51203170). Technical and human support provided by SGIker (UPV/EHU, MICINN, GV/EJ, ERDF and ESF) is gratefully acknowledged.

\section{References}

(1) Shah, A. A.; Hasan, F.; Hameed A.; Ahmed S. Biotech. Adv. 2008, 26, 246-265.

(2) Gross, R. A.; Kalra, B. Science 2002, 297 (5582), 803-807.

(3) Díaz, A.; Katsarava, R.; Puiggali, J. Int. J. Mol. Sci. 2014, 15, 7064-7123.

(4) Vilela, C.; Sousa, A. F.; Fonseca, A. C.; Serra, A. C.; Coelho, J.F.J.; Freire, C. S.

R.; Silvestre, A. J. D. Polym. Chem. 2014, 5, 3119-3141.

(5) Fujimaki, T. Polym. Deg. Stab. 1998, 59, 209-214.

(6) Yokohara, T.; Yamaguchi, M. Eur. Polym. J. 2008, 44, 677-685.

(7) Chrissafis, K.; Paraskevopoulos, K. M.; Bikiaris, D. N. Thermochim. Acta 2005, $435,142-150$.

(8) Iwata, T.; Doi, Y. Macromol. Chem. Phys. 1999, 200, 2429-2442.

(9) Sheng, L.; Register, R. A. Crystallization in Copolymers. Handbook of Polymer Crystallization, 2013; 327-346.

(10) Wang, G.; Qiu, Z. Ind. Eng. Chem. Res. 2012, 51, 16369-16376.

(11) Ren, M.; Song, J.; Song, C.; Zhang, H.; Sun, X.; Chen, Q.; Zhang, H.; Mo, Z. J. Polym. Sci.: Part B: Polym. Phys. 2005, 43, 3231-3241. 
(12) Zeng, J. B.; Huang, C. L.; Jiao, L.; Lu, X.; Wang, Y. Z.; Wang, X. L. Ind. Eng. Chem. Res. 2012, 51, 12258-12265.

(13) Ye H. M.; Wang, R. D.; Liu, J.; Xu, J.; Guo, B. H. Macromolecules 2012, 45, $5667-5675$.

(14) Mochizuki, M.; Mukai, K.; Yamda, K.; Ichise, N.; Murase, S.; Iwaya, Y. Macromolecules 1997, 30, 7403-7407.

(15) Papageorgiou, G. Z.; Bikiaris D. N. Biomacromolecules 2007, 8, 2437-2449.

(16) Díaz, A.; Franco, L.; Puiggali, J. Themochim. Acta 2014, 575, 45-54.

(17) Jeong, Y. G.; Jo, W. H.; Lee, S.C. Macromolecules 2000, 33, 9705-9711.

(18) Allegra, G.; Bassi, I. W. Adv. Polym. Sci. 1969, 6, 549-574.

(19) Pan, P.; Inoue, Y. Prog. Polym. Sci. 2009, 34, 605-640.

(20) Mincheva, R.; Delangre, A.; Raquez, J. M.; Narayan, R.; Dubois, P. Biomacromolecules 2013, 14, 890-899.

(21) Díaz, A.; Franco, L.; Estrany, F.; del Valle, L. J.; Puiggali, J. Polym. Deg. Stab. 2014, 99, 80-91.

(22) Baur, H. Makromol. Chem. 1966, 98, 297-301.

(23) Fillon, B.; Wittman, J. C.; Lotz, B.; Thierry, A. J. Polym. Sci., Part B 1993, 31, $1383-1393$.

(24) Müller, A. J.; Arnal, M. L. Prog. Polym. Sci. 2005, 30, 559-603.

(25) Lorenzo, A. T.; Arnal, M. L.; Sánchez, J. J.; Müller, A. J. J. Polym. Sci.: Part B: Polym. Phys. 2006, 44, 1738-1750.

(26) Müller, A. J.; Albuerne, J.; Márquez, L.; Raquez, J.-M.; Degée, Ph.; Dubois, Ph.; Hobbs, J.; Hamley I. W. Faraday Discuss. 2005, 128, 231-252.

(27) Müller, A. J; Arnal, M; Balsamo, V. Lecture Notes in Phys. 2007, 714, 229 259. 
(28) Castillo, R. V.; Müller, A. J.; Lin, M.-C.; Chen, H.-L.; Jeng, U.-S.; Hillmyer, M. A. Macromolecules 2008, 41, 6154-6164.

(29) Castillo, R. V.; Müller, A. J. Prog. Polym. Sci. 2009, 34, 516-560 (and references there in).

(30) Ihn, K. J.; Yoo, E. S.; Im, S. S. Macromolecules 1995, 28, 2460-2464.

(31) Ichikawa, Y.; Kondo, H.; Igarashi, Y.; Noguchi, K.; Okuyama, K.; J.

Washiyama, J. Polymer 2000, 41, 4719-4727.

(32) Ichikawa, Y.; Suzuki, J.; Washiyama, J.; Moteki, Y.; Noguchi, K.; Okuyama, K. Polymer 1994, 35, 3338-3339.

(33) Schultz, J. Front. Chem. China 2010, 5(3), 262-276.

(34) Weng, M.; Qiu, Z. ds.doi.org/10.1021/ma502019x/Macromolecules 2014, in press.

(35) Qiu, Z.; Ikehara, T.; Nishi, T. Macromolecules 2002, 35, 8251-8254.

(36) He, Y.; Zhu, B.; Kai, W.; Inoue, Y. Macromolecules 2004, 37, 3337-3345.

(37) Ikehara, T.; Kimura, H.; Qiu, Z. Macromolecules 2005, 38, 5104-5108.

(38) Lu, J.; Qiu, Z.; Yang, W. Macromolecules 2008, 41, 141-148.

(39) Yang,Y.; Qiu, Z. Ind. Eng. Chem. Res. 2012, 51, 9191-9197.

(40) Weng, M.; Qiu, Z. Macromolecules 2013, 46, 8744-8747.

(41) Papagerorgiou, G. Z.; Bikiaris, D. N. Polymer 2005, 46, 12081-12092.

(42) Yang, J.; Liang, J. -Z.; Li, F. -J. J. Macromol. Sci., Part B: Phys. 2012, 51, $1715-1730$.

(43) Papagerorgiou, G. Z.; Bikiaris, D. N.; Achilias, D. S. ; Papastergiadis, E.; Docoslis, A. Thermochim. Acta 2011, 515, 13-23.

(44) Krimm, S.; Tobolsky, A. V. J. Polym. Sci. 1951, 7(1), 57-76. 
(45) Hamley, W.; Castelletto, V.; Castillo, R.V.; Müller, A. J.; Martin, C. M.; Pollet, E.; Dubois, Ph. Macromolecules 2005, 38, 463-472.

(46) Hamley, I. W.; Parras, P.; Castelletto, V.; Castillo, R. V.; Müller, A. J.; Pollet, E.; Dubois, Ph.; Martin, C. M. Macromol. Chem. Phys. 2006, 207, 941-953. 
For Table of Contents use only

How composition determines the properties of isodimorphic poly(butylene succinate-ran-butylene azelate) random biobased copolymers: from single to double crystalline random copolymers

Idoia Arandia ${ }^{1}$, Agurtzane Mugica ${ }^{1}$, Manuela Zubitur $^{2}$, Arantxa Arbe $^{3}$, Guoming Liu ${ }^{4}$, Dujin Wang ${ }^{4}$, Rosica Mincheva ${ }^{5}$, Philippe Dubois ${ }^{5}$, Alejandro J. Müller ${ }^{1,6^{*}}$

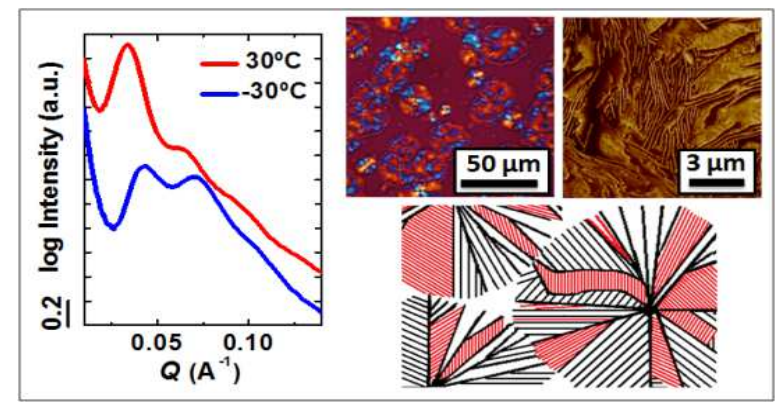

